\title{
Asset Prices in a News Driven Real Business Cycle Model $^{*}$
}

\author{
Aytek Malkhozov $^{\dagger} \quad$ Maral Shamloo
}

March 2010

\begin{abstract}
We examine the implications of introducing anticipated productivity shocks for the ability of a real-business-cycle model to explain asset prices. Our theoretical framework is a real-business-cycle model in which agents receive news about future productivity shocks. We show that incorporating anticipated shocks, or news, creates a persistent predictable component in consumption growth, often referred to as long-run risk in the finance literature (Bansal and Yaron, 2004). Thus, in conjunction with Epstein and Zin (1989) preferences and under plausible parameter calibrations, news shocks help explain key observed asset pricing facts. Furthermore, we show that news shocks improve our prediction for the co-movement of macroeconomic and financial variables, and explain the asset returns' lead over the business cycle. We also model time-varying economic uncertainty (stochastic volatility), and show how under certain conditions this could lead to lower premia in a model where consumption is endogenous. Finally, we discuss how a class of dynamic stochastic general equilibrium models with recursive preferences can be solved using perturbation methods, which are more computationally efficient than the usual numerical techniques.
\end{abstract}

Keywords : Anticipated Shocks, Long-Run Risk, Stochastic Volatility, Asset Prices and Aggregate Fluctuations, Perturbation Methods and Recursive Preferences

JEL Classification : G12, E32, E21, C63

${ }^{*}$ We thank Kosuke Aoki, Mikhail Chernov, Francois Gourio, Stephanie Schmitt-Grohe, Wouter den Haan, Christian Julliard, Leonid Kogan, Lars Lochstoer, Alex Michaelides, Stavros Panageas, Franck Portier, Bryan Routledge, Raman Uppal and Dimitri Vayanos for valuable comments.

${ }^{\dagger}$ London School of Economics, a.malkhozov@lse.ac.uk

${ }^{\ddagger}$ London School of Economics and International Monetary Fund, mshamloo@imf.org 


\section{Introduction}

Anticipated shocks are an important source of economic fluctuations. A strong intuition, confirmed by vast evidence, suggests that agents receive news about the future economic fundamentals. These changes in expectations have recently been incorporated in real business cycle models to explain macroeconomic co-movements. In this paper we extend the analysis to the asset pricing implications of news.

We start with a standard real business cycle model driven by productivity shocks and augment it along two dimensions. First, we incorporate anticipated shocks or shocks that affect productivity one or several quarters after they enter agents' information set. In our model shocks have an unanticipated component, as is often assumed in macroeconomic literature, but also an anticipated component. Anticipated shocks are news about movements in the productivity process that materialize in the future. Our second departure is to assume recursive preferences as suggested by Epstein and Zin (1989), Epstein and Zin (1991) and Weil (1989). Investors with Epstein-Zin preferences demand a premium for holding assets correlated with shocks to expected consumption growth, as well as the shocks to realized consumption growth.

Incorporating news improves macroeconomic fit. Our contribution is to show that news shocks are also important to match asset pricing facts. A strand of the consumptionbased asset pricing literature, pioneered by Bansal and Yaron (2004), relies on assumptions about the persistence of consumption growth, referred to as long-run risk, which, combined with Epstein-Zin preferences, allow to match the key asset pricing facts. A natural question is whether a standard production economy model can give rise to such dynamics in consumption growth and subsequently to the corresponding asset pricing results. News are important in the long-run risk context because they only affect the expected production possibilities of the economy. Following news about higher future productivity consumption responds both immediately and after the eventual productivity increase, generating persistence. The relative importance of substitution and income effects will determine the relative sizes of the responses. We show that anticipated shocks are an important channel to generate long-run risk in consumption without compromising the model's ability to fit the key macroeconomic variables and macro-finance co-movements. In particular, unlike the other mechanisms creating long-run risk - endogenous consumption smoothing and productivity growth persistence, news replicate the hump-shape in the auto-correlation function of quarterly consumption growth.

Our benchmark model with news matches important macro indicators such as consumption growth level, volatility and persistence, investment and output volatilities. The model matches the financial data well. The implied level of risk free rate and its volatility 
are in line with the data. We are able to generate significant risk premia for low values of relative risk aversion parameter.

Significantly, the model matches the lead of excess asset returns over the output growth very closely. This confirms that news are important to explain both macroeconomic and asset market dynamics. Anticipated shocks are a natural channel to account for the lead of asset prices over the business cycle. Prices are forward looking and incorporate news that will affect the productivity only in the future. Backus, Routledge, and Zin (2007), Backus, Routledge, and Zin (2008) and Garleanu, Panageas, and Yu (2009) point out that the lead of prices over quantities is an empirical fact unaccounted for by standard endowment and production economy models. In the latter paper the pattern is explained by the slow adoption of technological growth options. Our mechanism is purely informational and produces results quantitatively close to the data.

We extend the model by introducing time-variation in the volatility of productivity shocks. Extensive and detailed evidence in Bloom, Floetotto, and Jaimovich (2009) suggests that changes in macroeconomic uncertainty are another important driver of the business cycle fluctuations. We find that, unlike in endowment economies, incorporating stochastic volatility may fail to improve on asset pricing results. The changes in the volatility of productivity affect consumption volatility, but also create a persistent component in expected consumption growth. The endogenous correlation of stochastic volatility and long-run risk in consumption may reduce the risk premia and the predictive power of price-dividend ratios. This finding highlights the importance of real business cycle models that provide a theoretical justification for the assumptions made in endowment economy analysis. This is particularly relevant when the assumed properties of consumption dynamics are hard to establish empirically.

We solve the model by perturbing it around the non-stochastic steady state and using up to fourth order approximations in order to capture the effect of risk on asset prices. Our approach draws on Schmitt-Grohe and Uribe (2004) methodology for approximating a general class of dynamic stochastic general equilibrium (DSGE) models. Alternative methods, such as value function iteration, are infeasible because of the dimensionality problem. Our approach is well adapted for the problems with a large number of state variables, as the one we are dealing with in this paper, and is computationally efficient. Several recent papers, including Rudebusch and Swanson (2008a), Swanson, Anderson, and Levin (2006), Binsbergen van, Fernández-Villaverde, Koijen, and Rubio-Ramírez (2008) address the specific issue of using perturbation methods in the context of models with recursive preferences. In contrast, our paper shows how the usual framework can be applied. A companion note to this paper shows that the log-linearisation approach widely used in finance is a special case of second order perturbation. 
The importance of anticipated shocks has been documented in several recent papers that stimulated the interest in this line of research. In a VAR study Beaudry and Portier (2006) find that long-run movements in productivity explain a large fraction of business cycle fluctuations and cause standard business cycle co-movements. Moreover, these authors argue that anticipated shocks are highly correlated with the component in the innovations to stock prices which are orthogonal to productivity shocks. Schmitt-Grohe and Uribe (2008) estimate the importance of anticipated shocks using a structural model. We borrow the authors suggested shock structure and their quantitative estimates for the sizes of these shocks. Beaudry and Portier (2007) and Jaimovich and Rebelo (2009) explore how news about future productivity can generate a simultaneous increase in consumption, investment and working hours in a real business cycle model with real frictions. This strand of literature has not addressed the question of the impact of news on the prices of assets. We work in a simpler real business cycle framework and study both macroeconomics and asset pricing implications of anticipated shocks.

Tallarini (2000) is among the first to separate the relative risk aversion from the elasticity of intertemporal substitution in a real business cycle model in order to reconcile macroeconomic and asset pricing facts. The intuition is that the two parameters play distinct roles - the elasticity of intertemporal substitution allows to match macro dynamics while risk aversion determines the level of risk premia. This idea was further developed in Campanale, Castro, and Clementi (2009). In our work we show that elasticity of intertemporal substitution affects consumption dynamics, creating long run risk, and therefore can have an impact on asset prices.

We know of two previous attempts to understand whether long-run consumption risk is a realistic and reasonable feature in a production economy with endogenous consumption. Kaltenbrunner and Lochstoer (2007) answer in the affirmative by pointing out that in the simple real business cycle model i.i.d. shocks to productivity growth generate predictable movements in consumption growth provided the elasticity of intertemporal substitution is high enough. Croce (2008) introduces long run productivity risk and studies its implications for the endogenous consumption dynamics and asset prices. Relative to these papers we propose an additional source of persistence in consumption growth, namely anticipated shocks, which in addition to asset pricing facts matches several key macroeconomic and macro-finance co-movements.

Shocks to uncertainty have been advanced as an important impulse driving business cycles. Sim (2006), Justiniano and Primiceri (2008) and Fernández-Villaverde, GuerronQuintana, Rubio-Ramírez, and Uribe (2009) show the importance of volatility shocks for macroeconomic quantities using real business cycle models. To our knowledge Bloom 
(2009) presents the most comprehensive evidence on the uncertainty across the business cycle. This literature highlights the importance of capital adjustment costs and investment irreversibility to match macroeconomic responses to uncertainty shocks. While these papers argue that changes in uncertainty are most easily observable in financial markets they do not address the issue of asset pricing implications.

The importance of stochastic volatility for asset pricing in endowment economies has been highlighted by a series of papers including Bansal and Yaron (2004), Bansal, Kiku, and Yaron (2006), Bansal, Kiku, and Yaron (2007), Backus, Routledge, and Zin (2008), Beeler and Campbell (2009) to mention just some. Stochastic volatility is important for several distinct reasons. In Bansal and Yaron (2004) a persistent stochastic volatility process helps to explain returns predictability and also increases the level of risk premia. In Bansal, Kiku, and Yaron (2007) calibration the contribution of stochastic volatility relative to long-run risk to the volatility of stochastic discount factor is even more important. Backus, Routledge, and Zin (2008) point out that the correlation between stochastic volatility and long-run risk can help explaining the empirically documented lead of asset returns over consumption growth. Our contribution is to analyse which of the assumptions made in endowment economy models mentioned above are likely to emerge in general equilibrium with production.

The rest of the paper is organized as follows. Section 2 introduces the model. Section 3 briefly discusses our solution technique. Section 4 describes the structure of anticipated shocks Section 5 discusses our main results. Section 6 introduces stochastic volatility. In Section 7 we discuss the role of elasticity of intertemporal substitution, the modeling of equity and alternative preferences. Section 8 concludes.

\section{Model}

Our setup is a variant of a standard real business cycle model with one good, physical capital, endogenous labor input, and shocks to productivity. We extend the standard model by assuming recursive preferences, adding frictions in the form of adjustment costs to investment and allowing for news shocks. We exploit the second welfare theorem and find the equilibrium allocations by solving the social planner problem.

\subsection{Preferences}

The representative consumer maximizes a utility function defined recursively: 


$$
\underset{C_{t}, N_{t}}{\operatorname{Max}} U_{t}
$$

where

$$
\begin{aligned}
U_{t} & =\left(u_{t}^{1-1 / \psi}+\beta\left(E_{t}\left(U_{t+1}^{1-\gamma}\right)\right)^{\frac{1-1 / \psi}{1-\gamma}}\right)^{\frac{1}{1-1 / \psi}} \\
u_{t} & =\left(1-N_{t}\right)^{\eta} C_{t}
\end{aligned}
$$

The period utility $u_{t}$ is multiplicative in consumption $\left(C_{t}\right)$ and leisure $\left(1-N_{t}\right)$, reflecting the complementarity of leisure (see for example Eichenbaum, Hansen, and Singleton (1988)). This specification has two advantages over a utility separable in consumption and leisure. First, it ensures that period utility is always positive. Second, as emphasized by Rudebusch and Swanson (2008a), under separable utility the value function is not proportional to wealth, and therefore, $\gamma$ could not be interpreted as the coefficient of relative risk aversion. Whereas our specification ensures that the household's value function $V_{t}=\operatorname{Max}_{t}$ is proportional to $W_{t}^{1-\gamma}$, making $\gamma$ a direct measure of risk of aversion.

Unlike CRRA utility function, Epstein-Zin preferences allow us to separate the elasticity of intertemporal substitution from the coefficient of relative risk aversion (see Epstein and Zin (1989)). The parameter $\gamma$ stands for the agent's relative risk aversion and $\psi$, for his elastcity of intertemporal substitution. This separation has an important implication for the agent's preferences towards the early resolution of uncertainty. In the power utility case investor is indifferent towards the timing of resolution of uncertainty, if $\gamma>1 / \psi$ $(\gamma<1 / \psi)$ the investor prefers early (late) resolution of uncertainty. Intuitively, with $\gamma>1 / \psi$ the agent's propensity to smooth consumption across states is greater than his propensity to smooth consumption across time.

\subsection{Technology}

The consumption good is produced according to a constant returns to scale neoclassical production function

$$
Y_{t}=Z_{t}\left(A_{t} N_{t}\right)^{1-\alpha} K_{t}^{\alpha}
$$

where $K_{t}$ is the stock of capital, $N_{t}$ is the labor hours and $Y_{t}$ is the output. $Z_{t}$ and $A_{t}$ represent the stationary and non-stationary components of the total factor productivity respectively. We will describe their dynamics below. 
The law of motion of capital is given by

$$
K_{t+1}=K_{t}\left[(1-\delta)+\phi\left(I_{t} / K_{t}\right)\right]
$$

where $I_{t}=Y_{t}-C_{t}$ and $\phi$ is a positive, concave function, capturing the fact that capital adjustments are costly. We follow Jermann (1998) in specifying $\phi$ as below:

$$
\phi\left(I_{t} / K_{t}\right)=\left(\kappa_{1}\left(I_{t} / K_{t}\right)^{1-1 / \tau}+\kappa_{2}\right)
$$

The parameters $\kappa_{1}$ and $\kappa_{2}$ are set such that the adjustment cost is zero on the balanced growth path; i.e. $\phi(I / K)=I / K$ and $\phi^{\prime}(I / K)=1^{1}$. Note that $q_{t}=1 / \phi^{\prime}\left(\frac{I_{t}}{K_{t}}\right)$ is the marginal rate of transformation between new capital and consumption, or Tobin's $q$. Since $q_{t}=(I / K)^{-1 / \tau}\left(I_{t} / K_{t}\right)^{1 / \tau}$ we can interpret $\tau$ as the elasticity of investment-capital ratio with respect to Tobin's $q$.

We now introduce our specification for the technology shocks. The stationary $\left(Z_{t}\right)$ and non-stationary $\left(A_{t}\right)$ components of the productivity follow:

$$
\begin{aligned}
\ln A_{t+1}-\ln A_{t} & =x_{t+1}^{1} \\
\ln Z_{t+1} & =x_{t+1}^{2}
\end{aligned}
$$

We let $x^{1}$ and $x_{t}^{2}$ to be the first two elements of a first order auto-regressive vector $x_{t}$.

$$
x_{t+1}=H_{0}+H_{1} x_{t}+H_{2} \epsilon_{t+1}
$$

where $H_{0}$ is $(n \times 1), H_{1}$ is $(n \times n), H_{2}$ is $\left(n \times n_{\epsilon}\right)$ and $\epsilon_{t}$ is a vector of normally distributed innovations, $\epsilon_{t} \sim N\left(0, I_{n_{\epsilon}}\right)$. We assume all innovations are perfectly observable. This general specification nests several models as special cases: the standard growth model, the long-run productivity risk model (Croce (2008)), a model with anticipated shocks (Schmitt-Grohe and Uribe (2008)) as well as models with transitory shocks around a time trend in productivity growth (Kaltenbrunner and Lochstoer (2007)). We postpone the modeling of stochastic volatility until Section 6 .

\footnotetext{
${ }^{1}$ In particular, we set $\kappa_{1}=\frac{1}{1-1 / \tau}\left(\frac{I}{K}\right)^{1 / \tau}$ and $\kappa_{2}=\frac{1}{1-\tau}\left(\frac{I}{K}\right)$
} 


\subsection{Equilibrium}

The social planner's problem can be summarized by the Bellman equation

$$
\begin{gathered}
V\left(K_{t}, x_{t}\right)=\max _{C_{t}, N_{t}}\left(U_{t}\right) \text { or } \\
V_{t}=\max _{C_{t}, N_{t}}\left(\left(\left(1-N_{t}\right)^{\eta} C_{t}\right)^{1-1 / \psi}+\beta\left(E_{t}\left(V_{t+1}^{1-\gamma}\right)\right)^{\frac{1-1 / \psi}{1-\gamma}}\right)^{\frac{1}{1-1 / \psi}}
\end{gathered}
$$

where $V_{t}$ is the problem's continuation value or simply the value function. The maximization problem is subject to the production function (2), law of motion of capital (3) and the exogenous dynamics (5). It follows that the Euler equation and the optimal consumption-leisure trade-off can be written as (7) and (8) (see Appendix A for the derivation):

$$
\begin{aligned}
E_{t}\left[M_{t+1}\left(\frac{\partial K_{t+2}}{\partial C_{t+1}}\right)^{-1} \frac{\partial K_{t+1}}{\partial C_{t}} \frac{\partial K_{t+2}}{\partial K_{t+1}}\right] & =1 \\
-\left(1-N_{t}\right) \frac{\partial K_{t+1}}{\partial N_{t}}-\eta C_{t} \frac{\partial K_{t+1}}{\partial C_{t}} & =0
\end{aligned}
$$

where $M_{t+1}$ is the stochastic discount factor, defined as:

$$
M_{t+1}=\beta\left(\frac{V_{t+1}}{E_{t}\left(V_{t+1}^{1-\gamma}\right)^{\frac{1}{1-\gamma}}}\right)^{1 / \psi-\gamma}\left(\frac{C_{t+1}}{C_{t}}\right)^{-1 / \psi}\left(\frac{1-N_{t+1}}{1-N_{t}}\right)^{\eta(1-1 / \psi)}
$$

We assume perfect labor markets, and therefore wages are equal to the marginal product of labor. Hence, it is optimal for the representative firm to employ the level of labor chosen by the social planner and supplied by the representative agent.

\subsection{Asset Prices}

The focus of our analysis are equilibrium asset prices. In equilibrium the return on any asset $i, R_{t+1}^{i}$, satisfies

$$
E_{t}\left(M_{t+1} R_{t+1}^{i}\right)=1
$$

We define the one-period risk-free rate as

$$
R_{t}^{f}=E_{t}\left(M_{t+1}\right)^{-1}
$$


Following Alvarez and Jermann (2005) we choose to measure the volatility of the stochastic discount factor by its "entropy"

$$
L_{t}\left(M_{t+1}\right)=\log E_{t}\left(M_{t+1}\right)-E_{t} \log \left(M_{t+1}\right)
$$

The authors show that $L_{t}\left(M_{t+1}\right)$ places a bound similar to Hansen and Jagannathan (1991) on expected excess returns.

We also consider two particular assets. First, a claim on the aggregate consumption stream and second, a claim on the dividends paid out by the firms who own the capital stock. The dividend stream at time $t$ is defined as output net of investment and wages

$$
D_{t}=Y_{t}-W_{t} N_{t}-I_{t}
$$

The total returns - the sum of period flow and capital gain - on these two assets $R_{t}^{c}$ and $R_{t}^{d}$ substituted in the asset pricing equation (9) provide us with a recursive definition of the asset price or price-dividend ratio.

$$
\begin{aligned}
& \frac{P_{t}^{c}}{C_{t}}=E_{t}\left(M_{t+1} \frac{C_{t+1}}{C_{t}}\left(\frac{P_{t+1}^{c}}{C_{t+1}}+1\right)\right) \\
& \frac{P_{t}^{d}}{C_{t}}=E_{t}\left(M_{t+1} \frac{D_{t+1}}{D_{t}}\left(\frac{P_{t+1}^{d}}{D_{t+1}}+1\right)\right)
\end{aligned}
$$

It can be easily dealt with using perturbation methods. Alternatively, the return on firm equity could have been computed from the profit maximization problem of the representative firm (see Restoy and Rockinger (1994)) $)^{2}$.

Finally, we look at the real term premium. This provides us with an additional model implication and can be informative about the properties of the pricing kernel (see Alvarez and Jermann (2005)). We follow Rudebusch and Swanson (2008a) and model a real consol bond that pays a geometrically decreasing coupon every period. Again, its price can be written recursively

$$
P_{t}^{b}=1+\delta E_{t}\left(M_{t+1} P_{t+1}^{b}\right)
$$

where $\delta$ is the rate of coupon decay. By varying $\delta$ we can vary the duration of the bond ${ }^{3}$. The term premium is defined as the difference between the yield on the bond and its

\footnotetext{
${ }^{2}$ Explicitly, $R_{t+1}^{d}=\frac{1 / \phi^{\prime}\left(\frac{I_{t+1}}{K_{t+1}}\right)+d_{t+1}}{1 / \phi^{\prime}\left(\frac{I_{t}}{K_{t}}\right)}$, where $d_{t+1}=\alpha \frac{Y_{t+1}}{K_{t+1}}-\frac{\delta}{\phi^{\prime}\left(\frac{I_{t+1}}{K_{t+1}}\right)}-\frac{I_{t+1}}{K_{t+1}}+\frac{\phi\left(\frac{I_{t+1}}{K_{t+1}}\right)}{\phi^{\prime}\left(\frac{I_{t+1}}{K_{t+1}}\right)}$

${ }^{3}$ Explicitly, the duration of this bond is $1-\delta e^{-y}+\delta e^{-y} /\left(1-\delta e^{-y}\right)$, where $y$ is the bond yield.
} 
yield under risk neutrality

$$
T P_{t}=\log \left(\frac{\delta P_{t}^{b}}{P_{t}^{b}-1}\right)-\log \left(\frac{\delta \tilde{P}_{t}^{b}}{\tilde{P}_{t}^{b}-1}\right)
$$

\section{Perturbation Methods Solution}

We solve the model introduced in the previous section by expanding the value function, policy functions, and the laws of motion for the state variables around the non-stochastic steady state. This is the standard practice in macroeconomic literature since the closed form solution of the model is known at this particular point in the state-space. We opt for perturbation methods as opposed to numerical methods such as value function iteration or projection for two reasons: First, we would like to investigate a problem with a large number of state variables. The high dimensionality of the problem makes numerical methods computationally infeasible. Furthermore, perturbation methods are attractive as they obtain (approximate) analytical expressions for state-evolution equations and policy functions. Caldara, Fernández-Villaverde, Rubio-Ramírez, and Yao (2008) document the accuracy of perturbation methods in the context of models with recursive preferences and compare them with alternative computational approaches.

We follow the procedure suggested by Schmitt-Grohe and Uribe (2004) for finding a second-order approximation to the solution of a general class of discrete-time rational expectations models. Let the set of equilibrium conditions of the model we wish to approximate be written as

$$
E_{t} f\left(y_{t+1}, y_{t}, x_{t+1}, x_{t}\right)=0
$$

where $y_{t}$ is the vector of control variables and $x_{t}$ is a vector containing state variables. The solution to the recursively defined model is given by the equilibrium policy function for $y_{t}$ and the laws of motion for $x_{t}$ :

$$
\begin{aligned}
y_{t} & =g\left(x_{t}, \sigma\right) \\
x_{t+1} & =h\left(x_{t}, \sigma\right)+\sigma \eta \epsilon_{t+1}
\end{aligned}
$$

where $\sigma$ is a parameter scaling the size of uncertainty. Without loss of generality we can assume that $\sigma$ is either 0 , at the non-stochastic steady state, or equal to 1 otherwise. In general we don't need to specify the exact distribution of the vector of shocks. For each order of approximation we need to specify the corresponding moment 
We wish to approximate the functions $g$ and $h$ around the non-stochastic steady state, where $\sigma=0$ and $x_{t}=\bar{x}$. We define the non-stochastic steady state as vectors $(\bar{x} ; \bar{y})$ such that

$$
f(\bar{y}, \bar{y}, \bar{x}, \bar{x})=0
$$

Finding a second order approximation to the solution equations (11) and (12) involves solving for elements of the (matrix) derivatives of $g$ and $h$ with respect to $x$ and $\sigma$ evaluated at the steady state. They are found by differentiating (10) and evaluating the result at the steady state. This gives us a system of equations in the desired approximation coefficients. Schmitt-Grohe and Uribe (2004) provide an algorithm for solving this system. The resulting approximation is

$$
\begin{aligned}
{\left[g\left(x_{t}, \sigma\right)\right]^{i}=} & {[g(\bar{x}, 0)]^{i}+\left[g_{x}(\bar{x}, 0)\right]^{i}(x-\bar{x})+} \\
& \frac{1}{2}(x-\bar{x})^{T}\left[g_{x x}(\bar{x}, 0)\right]^{i}(x-\bar{x})+\frac{1}{2}\left[g_{\sigma \sigma}(\bar{x}, 0)\right]^{i}[\sigma][\sigma] \\
{\left[h\left(x_{t}, \sigma\right)\right]^{i}=} & {[h(\bar{x}, 0)]^{i}+\left[h_{x}(\bar{x}, 0)\right]^{i}(x-\bar{x})+} \\
& \frac{1}{2}(x-\bar{x})^{T}\left[h_{x x}(\bar{x}, 0)\right]^{i}(x-\bar{x})+\frac{1}{2}\left[h_{\sigma \sigma}(\bar{x}, 0)\right]^{i}[\sigma][\sigma]
\end{aligned}
$$

The authors show that the remaining terms of the Taylor expansion are zero $g_{\sigma}=h_{\sigma}=$ $g_{\sigma x}=h_{\sigma x}=0^{4}$. The fact that $g_{\sigma}=h_{\sigma}=0$ implies that the first order approximation is not affected by the volatility of the shock and produces no adjustment for risk. $g_{\sigma x}=$ $h_{\sigma x}=0$ implies that a second-order approximation can only produce constant risk premia. Furthermore, it can be shown that the risk aversion parameter $\gamma$ does not affect the nonstochastic steady state values. Neither does it enter the expressions for $h_{x}$ or $h_{x x}$ evaluated at the non-stochastic steady-state. $\gamma$ only enters in the term $h_{\sigma \sigma}$. This means that, to the second order, risk aversion only affects the difference between the stochastic steady state and the non-stochastic steady states but not the dynamics of the variables. Our benchmark is the second order approximation. As explained in the following sections we aslo do higher order robustness checks.

We can apply perturbation to any transformation of the variables. As it is standard in macroeconomics, we obtain a second order approximation in the logarithms of variables.

Since labour augmenting productivity process $A_{t}$ has a unit root our economy is growing. In order to find local approximations of state variables transition and policy functions around a particular point we need to transform the problem into a stationary one. For all the variables $X_{t}$ inheriting the unit root define $\tilde{X}_{t}$ as the variable normalized

\footnotetext{
${ }^{4}$ The general conjecture is that the derivatives of the policy function with respect to $x$ any number of times and with respect to $\sigma$ odd number of times evaluated at the non-stochastic steady state are zero provided the distribution of $\epsilon_{t+1}$ has corresponding odd moments equal to zero. We can explicitly show this up to the third order.
} 
by the unit-root technology shock, so that $\tilde{X}_{t}=X_{t} / A_{t-1}$. Define the stationary version of the value function to be $\tilde{V}_{t}=V\left(\tilde{K}_{t}, \tilde{A}_{t}, Z_{t}, \mu_{t}\right)$. Note that (2), (3), (5) and (1) are all homogeneous of degree one in $K_{t}$ and $A_{t}$. As a consequence $V_{t}$ is also homogeneous of degree one. We can rewrite the set of equations defining the equilibrium in terms of stationary variables. See Appendix B for details.

As compared to models with time-additive preferences the value function $\tilde{V}_{t}$ and the expression $E_{t}\left(\tilde{V}_{t+1}^{1-\gamma}\right)$ appear in the Euler equation and therefore have to be approximated. This posed problem for several previous attempts to apply standard perturbation techniques to models with recursive preferences. We treat the two variables as two additional controls and add two additional equations to the system of equilibrium conditions - one is the stationarised version of the definition of the value function, the other the definition of $E_{t}\left(\tilde{V}_{t+1}^{1-\gamma}\right)$ itself. See Appendix B for details.

In a companion note to this paper. Malkhozov and Shamloo (2009) show the exact relation of perturbation methods to log-linearisation techniques widely used in finance (see for example Bansal and Yaron (2004)). Exploiting the log-normality is equivalent to using all the first order and selectively some second order terms of the perturbation solution ${ }^{5}$.

\section{Anticipated Shocks}

\subsection{Introducing anticipated shocks}

We introduce news shocks in the real business cycle setting in order to account for the strong empirical evidence that most of the changes to productivity are anticipated one or several quarters in advance. The motivation for allowing news shocks is twofold. First, it is a reasonable generalization, especially when studying asset prices, that the information set of the agents contains more information than the current and the past realizations of the productivity shocks. Furthermore, there is strong empirical evidence which shows that anticipated shocks are important in explaining macroeconomic and financial variables. In a VAR study Beaudry and Portier (2006) find that technology shocks are first captured by stock prices before they affect productivity. Schmitt-Grohe and Uribe (2008) find that anticipated (stationary and non-stationary) shocks explain close to $70 \%$ of the variance of output growth, over $80 \%$ of the variance in consumption growth, and close to $50 \%$ of the variance in investment growth. As explained in detail further in this section, the

\footnotetext{
${ }^{5}$ Backus, Routledge and Zin (2007) apply log-linearisation to a real business cycle model. However, Malkhozov and Shamloo (2009) argue that their choice of equilibrium conditions to approximate is inconsistent.
} 
authors estimate the relative importance of different shocks within a real business cycle model. In this paper we take their suggested estimates on the relative importance of these shocks and ask how introducing anticipation (or enlarging the agents' information set) in an otherwise simple real business cycle framework affects quantities, prices and prices-quantities co-movements.

Schmitt-Grohe and Uribe (2008) and Jaimovich and Rebelo (2009) build models in which they include news shocks. The focus of these papers is to reproduce the correct macro dynamics and in particular neither paper studies the asset pricing implications and the macro-finance co-movements.

We study the hypothesis that news increase long-run risk in consumption. Anticipated shocks are not the only way to create long-run risk in consumption. Indeed, Kaltenbrunner and Lochstoer (2007) show that persistent time variation in expected consumption growth is a salient feature of real business cycle models even with unanticipated i.i.d. productivity shocks provided the propensity to smooth consumption is not too high (elasticity of intertemporal substitution not too low). In other words consumption long-run risk arises endogenously. An obvious way to amplify the effect is to increase the persistence in productivity shocks, which gives rise to persistent future movements in consumption.

Our framework allows for persistence in productivity shocks. The main contribution of our paper is to introduce shocks that will increase productivity not immediately but only one or several periods in the future. They lead to an expected increase in consumption at the period when technology improvement is realized. The relative importance of substitution and income effects will determine the sizes of the immediate response of consumption to the shock and the response after the eventual productivity increase.

Anticipated shocks are a natural channel through which we can explain the asset prices lead of the business cycle. This pattern has been reported in a number of empirical studies. Most recently this has been documented by Backus, Routledge, and Zin (2007) and Backus, Routledge, and Zin (2008) who show that both equity prices and term spreads lead the business cycle. Because asset prices are forward-looking, news about the future are incorporated in them but might not be reflected in the macroeconomic quantities as the anticipated shocks are yet to realize. Prices may contain more information than the history of macro variables. This is the simplest theoretical way to account for the predictive power of financial variables. 


\subsection{Structure of shocks}

The stationary and non-stationary productivity shocks are autoregressive and subject to anticipated $\left(\varepsilon^{1}, \varepsilon^{2}, \varepsilon^{3}\right)$ and unanticipated $\left(\varepsilon^{0}\right)$ innovations. This specification is taken from Schmitt-Grohe and Uribe (2008).

$$
\begin{aligned}
& x_{t}^{1}=\left(1-\rho_{A}\right) \lambda_{A}+\rho_{A} x_{t-1}^{1}+\varepsilon_{A, t}^{0}+\varepsilon_{A, t-1}^{1}+\varepsilon_{A, t-2}^{2}+\varepsilon_{A, t-3}^{3} \\
& x_{t}^{2}=\left(1-\rho_{Z}\right) \lambda_{Z}+\rho_{Z} x_{t-1}^{2}+\varepsilon_{Z, t}^{0}+\varepsilon_{Z, t-1}^{1}+\varepsilon_{Z, t-2}^{2}+\varepsilon_{Z, t-3}^{3}
\end{aligned}
$$

The agent learns about innovation $\varepsilon_{t}$ at date $t$ and it affects the productivity at the same date. Innovations $\varepsilon_{t-1}^{1}, \varepsilon_{t-2}^{2}, \varepsilon_{t-3}^{3}$ are anticipated one, two and three periods ahead they affect date- $t$ productivity, but are period $t-1, t-2, t-3$ information respectively. Therefore, at date $t$ the agent learns about 4 shocks $\varepsilon_{t}^{0}, \varepsilon_{t}^{1}, \varepsilon_{t}^{2}$ and $\varepsilon_{t}^{3}$, affecting productivity immediately and in one, two and three periods ahead. We assume all shocks are independent.

Additional lagged innovations can easily be incorporated in to the recursive formulation of the problem by increasing the number of state variables. The matrices $H_{0}, H_{1}$, and $H_{2}$ of the $\operatorname{VAR}(1)$ representation of the shocks are given in the Appendix D.

\subsection{Calibration}

Table 1 reports the values of the parameters which are constant across all models. All the parameters are calibrated at quarterly frequency. This is the frequency often used in analyzing the business cycle properties of macroeconomic aggregates. We set $\alpha$, the share of capital in the production function and depreciation rate of capital to standard values in business cycle literature (see Christiano, Eichenbaum, and Evans (2005)). The mean technology growth rate is set such that the output growth of the economy is around $2 \%$ annually. In this version of the paper, we assume a perfectly inelastic labor supply, i.e. we set $\eta=0$ and fix the size of the labor force at 1 . We will discuss this assumption and intend to release it in the future extensions of this paper.

We choose $\gamma=5$ for our benchmark calibration. We show that this value is enough to produce prices of risk in line with the data. We also discuss the results for $\gamma=10$. Changing the risk aversion only affects premia and the level of the risk free rate (which can changed by re-calibrating the discount factor), and essentially nothing else. This is exactly true in the second order approximation and is verified in higher order robustness checks. The fact that macroeconomic time series are essentially unaffected by the coefficient of relative risk aversion has been pointed out by Tallarini (2000). We calibrate $\beta$ to match the level of the risk free rate. 
We borrow our shock structure and the relative sizes of the anticipated and unanticipated innovations from the estimates by Schmitt-Grohe and Uribe (2008). It is worthwhile to emphasize that there are important differences between the model we consider and their estimated model ${ }^{6}$. Despite these modeling differences, their exercise is uniquely useful to us for disciplining our calibration of anticipated shocks. Table 3 reproduces the estimated variances for all of the components of the shocks, reported in Schmitt-Grohe and Uribe (2008). We weight all the variances by a factor $\chi$ to achieve the level of consumption volatility observed in the data.

Perturbation solution allows for easy estimation of the model. This is one of the most interesting potential extensions to our paper. The first Bayesian estimation results for our model suggest that Schmitt-Grohe and Uribe (2008) identification of shocks is a good approximation. For this exercise we have used macroeconomic data on consumption, output and investment only. Our aim is the identification of anticipated and non-anticipated shocks, along with the key parameters of the model, using both macroeconomic and financial data.

\section{Results}

In this section we present the results of four calibrations of our model. Model I is our benchmark. It includes anticipated and non-anticipated non-stationary productivity shocks. Model II is identical to model one except for all the uncertainty is coming from unanticipated innovations. The comparison of the two models allows us to isolate the anticipation effects. Model III includes stationary in addition to non-stationary news shocks. Finally in Model IV we increase the relative risk aversion coefficient from 5 to 10.

\subsection{Macro responses}

Macroeconomic literature on news in real business cycles focuses on generating a "boom" in consumption, investment and hours worked following a news shock. This is the

\footnotetext{
${ }^{6}$ First, we differ in our preference specifications. We assume Epstein-Zin preferences to study the effects of long-run risk, whereas Schmitt-Grohe and Uribe (2008) assume habit formation in consumption and leisure. Second, the authors introduce capacity utilization, which plays an important role in creating the correct co-movements of macro aggregates. Third, (in the current version of the paper) we ignore labor supply decisions by assuming a perfectly inelastic labor supply. The authors also include investment specific productivity shocks and government shocks in their model. However, after estimating the full information model, they show that productivity shocks (stationary and non-stationary) account for $98 \%$ of output growth volatility and $100 \%$ consumption growth volatility. This suggests that ignoring investment specific and government shocks in our model should have little effect on our predictions about business cycle properties of macroeconomic time-series.
} 
main issue in for example Beaudry and Portier (2007), Schmitt-Grohe and Uribe (2008), Jaimovich and Rebelo (2009). A standard real business cycle model generates a big fall in investment and an increase in consumption in response to a positive change in expectations about productivity. This result is not supported by the data. We do not include any of the real rigidities or habits the above papers use to change this outcome. Instead, Epstein-Zin preferences allow us to set elasticity of intertemporal substitution to a value greater than 1, thus mitigating the wealth effect which is the cause of the standard model responses.

Figure 1 displays the impulse responses to two types of non-stationary productivity shock, namely an unanticipated and a one-quarter anticipated shock to the non-stationary component of total factor productivity $\left(\varepsilon_{A}^{0}\right.$, shown in solid and $\varepsilon_{A}^{1}$, shown in crossed line respectively). All variables are measured in percent deviation from the de-trended non-stochastic steady state. Responses to unanticipated component are standard. In response to the 1-quarter anticipated non-stationary shock productivity remains at the steady state level until period 2 and stays high thereafter. Consumption increases in anticipation of the increase in productivity next period. However this increase is smaller if the elasticity of intertemporal substitution is larger. For values of elasticity higher than in our calibration $(\psi \approx 2.5)$ consumption actually falls. Note that output does not increase. This is because productivity has not changed and capital is fixed. We also assume constant labor ${ }^{7}$. Because of this resource constraint there are less resources available for investment. Therefore, capital stock falls slightly and then rises (this pattern will be reflected in dividend flows, as we will observe later). Endogenous labor choice could potentially generate a simultaneous increase in consumption, investment and hours worked. But the preferences over consumption and labor we assume in the general case of the model do not allow for labor supply elastic enough.

Figure 2 shows the response to a three-quarter anticipated stationary productivity shock (crossed line) and the response to an unanticipated stationary productivity shock (solid line). In response to the anticipated shock, consumption rises immediately, even though the productivity increase has not materialized. Between the announcement and the actual increase in productivity, output is roughly constant, decreasing only slightly due to the decreasing capital stock and capital decreases for the same reason as above: The absence of adjustment costs do not bring forward future needs to increase investment. But higher consumption, without an increase in output results in a temporary reduction in investment and capital stock levels. The capital stock rises slowly after the shock is materialized. Note that this model does not produce the hump-shaped response of output

\footnotetext{
${ }^{7}$ And no time-varying capital utilisation.
} 
in response to stationary shocks, which is typically found in VAR studies (but it does create a hump-shaped response in consumption).

Looking at the macro statistics in Table 4, we observe that the benchmark model with news (Model I) matches the volatilities of consumption, output and investment, improving on the performance of the model without anticipation effect (Model II). We do not need to include adjustment costs or any other real frictions in order to obtain accurate volatilities. In general we believe that real frictions such as capital adjustment costs are a realistic feature of the economy and are necessary to explain a number macroeconomic stylized facts. However, in this paper we show that some of the implications of including real frictions in a real business cycle model can also be achieved by assuming a richer shock structure instead.

As expected, news naturally increase consumption auto-correlation. See Figure 3. Lower order autocorrelations are in line with the data, however higher order autocorrelations do not decrease as rapidly. News help to reproduce the hump shape in the autocorrelation function.

In the standard real business cycle models all the aggregate quantities co-move together (Model II). Introducing news allows to decouple the movements in consumption, output and investment. Model II performance is not satisfactory enough. In particular, correlation of consumption and investment growth is negative. As was noted before it is not possible to increase both consumption and investment in response to the news shock if working hours stay constant. Endogenous labor choice with homothetic preferences over consumption and leisure cannot generate the desired hours response. Including stationary shocks (Model III) improves on the explanation of the co-movements of macroeconomic time series. This finding is consistent with Schmitt-Grohe and Uribe (2008) who argue that both stationary and non-stationary news shocks are important to explain macroeconomic dynamics.

\subsection{Asset prices}

The benchmark calibration of the model (Model I) produces the level of the risk free rate and its volatility that are in line with the data and at the same time generates high prices of risk. News increase the volatility of the stochastic discount factor as measured by its entropy. Indeed, anticipated shocks created more persistence, or long-run risk, in consumption growth which translated into higher pricing of risk. Compared to the model without anticipation (Model II) the premium and the Sharpe ratio of the consumption claim also increase. For instance the Sharpe ratio is 0.46. If stock-market is modeled as 
a levered claim on consumption stream or aggregate dividends as a process more volatile with consumption but highly correlated with it, the model will match the equity premium observed in the data.

In Model III we add stationary news shocks, which as we have seen in previous subsection are important for macroeconomic dynamics, to our benchmark. Consistent with Kaltenbrunner and Lochstoer (2007) we also find that only non-stationary shocks matter for asset pricng. Stationary shocks create additional volatility in macro variables. Keeping consumption volatility constant at the level observed in the data, the volatility of the stochastic discount factor decreases. However, the Sharpe ratio of the consumption claim is still in line with the one of the stock-market.

We have achieved the results above with a conservative assumption about the coefficient of relative risk aversion, namely $\gamma=5$. In Model IV we set this parameter to 10 . Changing the risk aversion only affects the risk free rate level and the pricing of risks. The volatility of the stochastic discount factor and the Sharpe ratio of the consumption claim rise dramatically.

Real term premium is negative in all calibrations. In our setup, as interest rates fall in a recession, long term real bonds are a hedge and therefore command a negative premium. The observed positive nominal term premium is therefore a purely monetary phenomenon. While data on real rates are not easily available and complete, Rudebusch and Swanson (2008a) argue that real term premium is indeed negative.

While the pricing of risks in the economy is satisfactory all the calibrations fail to price the dividend claim correctly. This paradox is documented in Kaltenbrunner and Lochstoer (2007). The Sharpe ratio of the dividend process in the calibration without news (Model II) is equal to the ratio of the consumption claim. This is not surprising as all the aggregate variables move togehter. However, the volatility of excess returns and the level of risk premium are to low to be consistent with the data even when magnified by any reasonable leverage. In the models that include news Sharpe ratio actually falls, even though the stochastic discount factor is more volatile. Clearly, the dividend process that arises endogenously in our model is counterfactual. Table 6 summarises the properties of the aggregate dividends and confirms this. In Model II dividends are strongly negatively correlated to consumption growth. In Model I they co-move positively with consumption but are negatively auto-correlated. Let us analyse the intuition. Dividends can be written as

$$
D_{t}=\alpha Y_{t}-I_{t}
$$

In Model II consumption, output and investment move together in response to an unanticipated shock. With higher elasticity of intertemporal substitution investment is 
higher. Dividends sensitivity to the output increase is only $\alpha$, therefore dividend can actually become negative after the shock. This result is in line with Kaltenbrunner and Lochstoer (2007). In Model I dividends rise after the news shock at the same time as consumption. However, as investment starts to increase after the effective increase in productivity, dividends drop. An increase in output due to higher working hours could improve on the properties of dividends.

Results, not reported in this version of the paper, suggest that increasing significantly the capital adjustment costs increases the premia for the dividend claim to the levels compatible with the data. Capital stock becomes costly to change and is therefore more risky. The solution goes back to Jermann (1998) and essentially does not rely on long run risks or news. However, introducing adjustment costs changes dramatically the internal mechanisms of the model. In Section 7 we discuss the shortcomings of real business cycle models that lead to the poor results on the pricing of the dividend claim.

\subsection{Macro-finance co-movements}

Our model is able to match the lead of the asset prices over the business cycle. This empirical finding was one of the main motivations for introducing news in a real business cycle model and the results suggest that news are indeed important to explain asset returns and macroeconomic fluctuations jointly.

We focus on the leads and lags structure of excess returns on consumption claim and output. Figure 4 shows that the model without news (Model II) imply a pattern where contamporaneous (quarterly) excess returns and output growth are strongly correlated while leads and lags are very close to zero. In the data excess returns with one to three quarters lag are correlated with the output growth, while contamporaneous correlation is low. This pattern is reproduced by our model. Figures 4 and 5 show that the lead and lag correlation structure generated by news Models I and III is very close to the data.

\subsection{Time variation in risk premia}

The risk premia reported in the previous section - aggregate consumption claim premium, aggregate dividend claim premium and real term premium - are exactly constant. This is the result of limiting ourselves to the second order approximation of the soltion rather than a feature of the model itself. Rudebusch and Swanson (2008a) study the nominal term premium in a related DSGE setup. They approximate their model to the third order and find non-negligible time variation in the term premium. Furthermore, allowing 
for elasticity of intertemporal substitution to be greater than the inverse of the coefficient of the relative risk aversion increases the volatility of the term premium compared to the CRRA case.

Approximating our benchmark model to the third order makes the risk premia timevarying. Yet their volatility is negligible and they are not correlated with macro variables. The standard deviations of consumption and dividend claims premia are of the order of $10^{-3}$ percents. This can be compared to their levels reported in this section.

We can think of two reasons explaining the difference in results with Rudebusch and Swanson (2008a). First, we study different phenomena within different albeit related frameworks. Second, the authors introduce non-homogeneous preferences over consumption and leisure. Their model is naturally non-homothetic and heteroscedastic leading to time-varying premia. We assume homothetic preferences which allow us to have a unit root productivity process.

\section{Stochastic Volatility}

\subsection{Introducing stochastic volatility}

A literature going back to Campbell and Shiller (1988) finds that excess returns are predicted by a host of state variables. In particular vast evidence suggests that high dividend yields predict a rise in future expected returns. The idea of time-varying premia has the appealing interpretation that risk and/or risk aversion vary across the business cycle. It is also standard empirical finding that the conditional variance of the market return fluctuates across time and is very persistent (see, for instance Bollerslev, Engle, and Wooldridge (1988)). The model in Section 2 is buffeted by homoscedastic productivity shocks and we show that endogenous dynamics of quantities and prices are also essentially homoscedastic. Our preferences structure only allows for constant relative risk aversion. In order to capture the time-variation in economic uncertainty we will relax the homoscedasticity assumption.

In the endowment economy literature, a common way for capturing time-varying risk premia is to introduce time variation in the conditional volatility of consumption and dividend growth. It is important to separate two distinct roles for stochastic volatility in such models. On the one hand, introducing stochastic volatility in consumption growth gives rise to time-varying premia. Moreover, as changes in volatility affect the pricedividend ratio, it will predict the variation in risk premia. The second effect of introducing stochastic volatility, combined with Epstein-Zin preferences, is its impact on the level of 
the premia. In Bansal and Yaron (2004) it accounts for 39\% of the volatility of the stochastic discount factor (compared to $47 \%$ for the long-run and $14 \%$ for the short-run risks) and results in the market compensation for changing economic uncertainty of about $1.2 \%$ per annum. Beeler and Campbell (2009) argue that this contribution is even more important in other calibrations such as Bansal, Kiku, and Yaron (2007).

In this section we aim to understand whether introducing time-varying uncertainty in a general equilibrium model with production allows us to replicate the two results achieved in the endowment economy model. Our model is driven by productivity shocks. Therefore we introduce time-varying economic uncertainty by assuming that the productivity growth has a time varying volatility.

Evidence supports the stochastic volatility in productivity growth assumption. Croce (2008) reports the results of a GARCH study that show the variations in the volatility of productivity growth. Justiniano and Primiceri (2008) provide evidence on the time variation of productivity shocks volatility based on a structural estimation of a DSGE model. Bloom, Floetotto, and Jaimovich (2009) provide extensive aggregate, industry and firm-level empirical evidence on the time variation of macroeconomic uncertainty and claim it is an important source of macroeconomic fluctuations. The authors build a model in which investment and labor market frictions allow them to match the responses of macroeconomic quantities to a change in the volatility of productivity shocks. We study stochastic volatility in a simpler, no-frictions setup and derive asset pricing implications.

Intuitively, we expect that introducing time-varying variance of productivity growth, will result in time-varying variance of consumption growth. However, changes in uncertainty will also affect the optimal consumption choice creating joint consumption growth and consumption volatility dynamics. We look at the asset pricing implications of this interaction which is usually assumed to be zero in endowment economy models. For analytical and computational tractability in this section we abstract from anticipated shocks.

\subsection{Specification and calibration}

In this section we would like to focus on the effects of stochastic volatility. We assume a simple growth model with no anticipated shocks as well as no endogenous labor choice or real frictions.

$$
\begin{aligned}
x_{t+1}^{1} & =\lambda_{A}+\sigma_{t} \varepsilon_{t+1} \\
x_{t+1}^{2} & =0
\end{aligned}
$$


We depart from the general model in 2 and specify the productivity growth variance as a process

$$
\sigma_{t+1}^{2}=(1-\varphi) \theta+\varphi \sigma_{t}^{2}+\omega \xi_{t+1}
$$

where $\xi_{t+1} \sim N(0,1)$. This is the form used in finance literature discussed above. For simplicity, we assume that innovations to productivity growth and its volatility are uncorrelated $E_{t}\left(\varepsilon_{t+1} \xi_{t+1}\right)=0$.

Our calibration of productivity stochastic volatility is guided by the Bansal and Yaron (2004) calibration of stochastic volatility in consumption. In other words, our benchmark calibration for monthly productivity is such that the resulting consumption volatility is the same as in Bansal and Yaron (2004). In particular, we match the long-term volatility level, volatility persistence and the volatility of volatility assumed by the authors.

Table 8 presents the parameter values used in the Bansal and Yaron (2004) calibration for consumption variance with the corresponding implied calibration for productivity variance parameter. We back-engineering the productivity parameters using an analytical log-linearisation of the model from Malkhozov and Shamloo (2009). Appendix E shows the form of the consumption variance process implied by the log-linearisation. Note that for the same stochastic volatility in consumption, the implied productivity volatility parameters vary with the other parameters in the model, notably the elasticity of intertemporal substitution. These parameters, consistent with Bansal and Yaron (2004), are reported in Table 7 .

To capture the dynamics effects of stochastic volatility with perturbation methods, we use the fourth order expansion ${ }^{8}$.

\subsection{Stochastic volatility results}

Our results can be summarised in two points. First, stochastic volatility does not significantly affect macroeconomic moments. Our calibration of the productivity variance creates very persistent but low magnitude movements in volatility which affect asset prices but not macroeconomic quantities. Table 9 compares the key macro moments in a model with heteroscedastic productivity shocks, and an identical model where we shut off the stochastic volatility ${ }^{9}$.

\footnotetext{
${ }^{8}$ One intuition is that stochastic volatility affects the skewness and the kurtosis of the distribution of the variables in the model, while each order of approximation allows to capture an additional moment. However the former statement is about the unconditional distribution, the latter about conditional one. Our preferred interpretation is related to the mechanics of how uncertainty is scaled in perturbation methods and has no obvious economic intuition behind.

${ }^{9}$ Note that this is not the same as the model in Section 4, because we are abstracting from news and change the calibration frequency.
} 
The second important result is related to the asset pricing implications of optimal consumption responses to variance shocks. We find that changes in volatility of productivity affect both consumption volatility and expected consumption growth: an increase in uncertainty increases consumption growth volatility but is also associated with higher expected future consumption.

As can be seen on Figure 6, a positive variance shock leads to an immediate drop in consumption as agents increase their buffer stock savings. As there is no change in the actual productivity of the economy, this leads to an increase in investment, future output and, importantly, future consumption. Moreover, as the volatility reverts to its long-term mean consumption converges to the steady state.

In Bloom, Floetotto, and Jaimovich (2009) an increase in uncertainty first leads to a short recession, followed by the response similar to the one produced in our model. In their model higher volatility forces the firms to delay investment projects in the short run because they face labor and capital adjustment costs. Unlike the authors we assume no labor market and investment frictions in this version of the model.

An increase in uncertainty leads to a drop in the price of the consumption claim (see Figure 6). Optimal consumption falls immediately after the shock but is expected to go up. With relative risk aversion greater than the inverse of the elasticity of intertermporal substitution the correlation of the asset returns with changes in expected consumption growth is more important than the correlation with contemporaneous consumption drop. This explains the asset pricing results reported in Table 10. The risk premium and the Sharpe ratio of the consumption claim decrease as compared to the benchmark without stochastic volatility.

What are the endogenous consumption dynamics? Stochastic volatility of productivity has two effects. First, the volatility of consumption growth is stochastic. Second, the level of volatility positively affects expected consumption growth creating endogenously a longrun risk component. The two are positively correlated and work in opposite directions in affecting asset prices. Moreover, the volatility of consumption growth is endogenously negatively correlated to the consumption growth itself $\left(\operatorname{corr}\left(\Delta c, \Delta \sigma_{c}^{2}\right)=-0.24\right)$ creating negative correlation between innovations to expected consumption growth and realised consumption growth. See Appendix E for a representation of these dynamics.

Risk premia are time varying. Indeed they vary exactly with the level of variance. However, as the price-dividend ratio is affected both by the persistent variations in volatility and the corresponding long run risk component, which work in opposite directions, the predictive power of dividend yields over returns is reduced. 
It is interesting to contrast these results with the assumptions made in endowment economy models. We show that consumption dynamics obtained endogenously in general equilibrium are unlikely to have the properties assumed by the authors and therefore will not support the corresponding asset pricing results. We find that shocks to consumption growth variance and realised consumption growth are correlated, while they are assumed to be independent in Bansal and Yaron $(2004)^{10}$. Of crucial importance for asset pricing is the finding that in equilibrium consumption growth variance and expected consumption growth are driven by the same latent factor.

Backus, Routledge, and Zin (2008) show that assuming expected consumption growth to be positively related to volatility helps to match the lead-lag of asset prices over the business cycle. This particular feature of volatility process arises endogenously in our model. We would like to explore the implications of our model for the macro-finance co-movements in future extensions of this paper.

\section{Discussion}

\subsection{Role of the elasticity of intertemporal substitution}

The pricing of long run risks in endowment and production economies can be understood by looking at assets as both intertemporal and interstate consumption smoothing devices. Bhamra and Uppal (2006) provide a good intuition for the respective role of relative risk aversion and elasticity of intertemporal substitution in portfolio-consumption choice. Consumption and portfolio decisions depend on both risk aversion and elasticity of intertemporal substitution. However, the sign of the intertemporal hedging component in the optimal portfolio depends only on the size of the risk aversion relative to unity, while only the magnitude of the hedging portfolio depends on the elasticity of intertemporal substitution. The role of the parameters is reversed for the optimal consumption rule.

Lets first consider a Lucas-tree economy. A positive shock to expected consumption growth (or a negative shock to uncertainty) increases wealth to consumption ratio, which adjusts through movements in wealth since consumption is exogenous. This adjustment depends on the size of the elasticity of intertemporal substitution. If the substitution effect dominates the wealth effect, i.e. elasticity of intertemporal substitution is greater

\footnotetext{
${ }^{10}$ This can be reverted by assuming that innovations to productivity growth and its volatility are correlated, for example that $E_{t}\left(\varepsilon_{t+1} \xi_{t+1}\right)<0$. The discussion of the correlation between uncertainty and productivity growth is beyond the scope of this paper. We refer the readers to specialised literature, e.g. Ramey and Ramey (1995).
} 
than one, the agent would like to hold more of the asset, thus driving prices up. Otherwise (when elasticity of intertemporal substitution is less than 1) the agent prefers bringing the increase in consumption forward, depressing prices.

How does this matter for risk premia? Shocks to expected consumption growth affect expected future returns to wealth. The agent with relative risk aversion greater than 1 wants to hedge against these changes in the investment opportunity set (and bet on them if relative risk aversion is less than one). Notice that relative risk aversion and inverse of the elasticity of intertemporal substitution are comparable measures of propensity to smooth consumption across states and time respectively. Therefore if the two are equal (CRRA case) the changes in wealth-consumption ratio exactly offset the hedging demand. With Epstein-Zin preferences there can be a wedge between relative risk aversion and the inverse of the elasticity of intertemporal substitution which will translate into premia. As an example, consider an agent with both elasticity of intertemporal substitution and relative risk aversion greater than 1 , exposed to a positive shock to expected consumption growth. The intertemporal substitution effect drives up asset prices. The hedging demand effect would imply that the agent wants his portfolio to depreciate. Therefore a premium is required for the agent to hold the asset in equilibrium. If consumption and dividends are correlated the results for the pricing of aggregate risk carry forward to the risk premium for the claim on aggregate dividends. Recursive preferences are crucial for this mechanism.

In production economies the analysis is slightly different as we cannot take consumption as given but have match it give our assumptions about the preferences. Increasing the elasticity of intertemporal substitution decreases the volatility of consumption growth and increases its autocorrelation. The intuition is the following. With low values of elasticity of intertemporal substitution the wealth effect dominates and the agent increaseases his consumption immediately rather than invest to take advantage of the positive technology shock. Consumption growth is not spread through time but occurs (close to) instantaneously with a volatility close to that of the productivity shock. Therefore the unconditional volatility of consumption is high and the persistence of consumption growth is low. Raising elasticity of intertemporal substitution decreases the short-run component of risk and increases the long-run component. Moreover, the importance of the long-run risk increases with increased wedge between relative risk aversion and the inverse of the elasticity of intertemporal substitution as the agent is willing to resolve intertemporal risk sooner. Overall the two effects do not cancel each other, the risk premium for the consumption claim (aggregate wealth) goes up. See the comparative statics of the model with respect to the elasticity of intertemporal substitution on Figure 7.

Things might be different with stationary shocks. In an AK production economy subject to time-varying mean and variance of productivity Malkhozov (2009) show that 
the elasticity of intertemporal substitution is irrelavant for the prices of risk. Endogenous consumption choices make the Better asset pricing results can be obtained only by decreasing the volatility of consumption given the shocks size by varying the elasticity of intertemporal substitution.

\subsection{Definition of equity}

As explained in Section 5 the endogenous dividend dynamics are counter-factual. We also suggested that one way to deal with this issue is to introduce capital adjustment costs as in Jermann (1998).

One of the conceptual difficulties of studying equity premia in a real business cycle framework is the definition of a counterpart for equity in the model. The common approach is to look at the marginal product of capital or the return on the dividend claim. We argue that this has some undesirable implications. Most importantly, it does not allow us to separate the asset pricing part of the model from the employment and wages part (which are usually not the focus of such papers). This comes about because dividends are defined as consumption minus wages, and therefore a model generating realistic consumption dynamics but failing on employment and wages, will inevitably produce unrealistic dividends and thus asset pricing implications. In this paper, we circumvent the imperfect modeling of the labor market by focusing on the most generic asset i.e. the consumption claim.

Another issue is leverage. Literature has usually assumed constant leverage which preserves the Sharpe ratio but magnifies the level of return volatility and premia. A good alternative approach is to explicitly model equity and debt as in Gomes and Schmid (2009) so that equilibrium dividend process is determined in a more realistic way. The authors embed an endogenous capital structure model in a simplified production economy in order to study the lead of asset prices and spreads over the business cycle. We aim to incorporating capital structure in our framework as a future extension.

\subsection{Alternative preferences}

Habit formation has been advanced as an important alternative to the standard preferences specification in both endowment and real business cycle models. We take the view that the Epstein-Zin utility specification imposes less structure on the preferences of the agent than the habit formation specification, as it only assumes constant elasticity of intertemporal substitution and relative risk aversion coefficients. Models with habit 
formation claim a partial success in the Lucas-tree setup: they achieve high equity risk premia at the cost of volatile interest rates. However, simply introducing habit formation in a production economy does not generate the desired asset pricing implications. The agent has a strong desire for smoothing consumption yet he can achieve this without generating fluctuations in equity returns (see Boldrin, Christiano, and Fisher (2001)).

In the context of a news-driven business cycle Schmitt-Grohe and Uribe (2008) and Jaimovich and Rebelo (2009) both assume habit formation utility functions (albeit with some differences) in order to match the macro-economic co-movements. In particular the preferences are designed in such a way to mitigate the wealth effects of an anticipated productivity shock and generate a boom in investment in response to it. The EpsteinZin preferences address this issue, at least partially, since the elasticity of intertemporal substitution coefficient is set to be greater than 1 .

A related work by Rudebusch and Swanson (2008a), Rudebusch and Swanson (2008b) compares the performance of DSGE models with habit formation vs. recursive preferences and nominal long-run risks for the pricing of bonds. The authors find that the model with Epstein-Zin preferences produces better joint results for the macroeconomic variables and the bond yields.

\section{Conclusion}

In this paper we study the asset pricing implications of a stochastic growth model with recursive preferences and a general shock structure, which allows for news shocks. The aim is to investigate whether asset prices obtained in an endowment economy with longrun risks can be replicated in a production economy framework, while at the same time matching key macroeconomic variables. Schmitt-Grohe and Uribe (2008) show that news shocks are important in explaining business cycle movements of the main macroeconomic variables. In this paper, we discuss their asset pricing implications.

The model is subject to stationary and non-stationary productivity shocks, each of which have an unanticipated component as well as anticipated components at 1, 2, and 3 quarter horizons. We solve the model by a second order perturbation technique and show how standard perturbation methods can be applied to models with recursive preferences.

Our benchmark calibration can match the main macroeconomic moments in the data such as volatility of consumption, output, and investment growth. It also produces financial moments in line with those observed in the data: low level and low volatility risk free rates and high risk premia and Sharpe ratios. We achieve these results without resorting 
to unusual parameter values for elasticity of intertemporal substitution or risk aversion. In our benchmark calibration, we choose an elasticity of intertemporal substitution of 1.5 and a relative risk aversion coefficient of 5. Importantly, our model is able to match the lead-lag structure of asset excess returns and macroeconomic variables.

Independently we consider the problem of stochastic volatility in the production economy. We find that consumption growth volatility dynamics assumed in several popular long-run risk model calibration are unlikely to arise in general equilibrium.

Solving DSGE models with perturbation methods has an important advantage over other numerical procedures which has not been explored in this thesis. Perturbation solution allows us to easily estimate the model. Taking the model directly to the data and estimating the importance of the news shocks at various horizons using jointly macroeconomic and asset prices time series is an interesting direction of future research. 


\section{References}

Alvarez, F., and U. J. Jermann (2005): "Using Asset Prices to Measure the Persistence of the Marginal Utility of Wealth," Econometrica, 73(6), 1997-2016.

Backus, D. K., B. R. Routledge, and S. E. Zin (2007): "Asset Prices in Business Cycle Analysis," .

(2008): "The Cyclical Component of US Asset Returns," .

Bansal, R., D. Kiku, and A. Yaron (2006): "Risks for the Long Run: Estimation and Inference," .

- (2007): "A Note on the Economics and Statistics of Predictability: A Long Run Risks Perspective," .

Bansal, R., and A. Yaron (2004): "Risks for the Long Run: A Potential Resolution of Asset Pricing Puzzles," The Journal of Finance, 59(4), 1481-1509.

Beaudry, P., and F. Portier (2006): "Stock Prices, News, and Economic Fluctuations," American Economic Review, 96(4), 1293-1307.

- (2007): "When can changes in expectations cause business cycle fluctuations in neo-classical settings?," Journal of Economic Theory, 135(1), 458-477.

Beeler, J., And J. Y. Campbell (2009): "The Long-Run Risks Model and Aggregate Asset Prices: An Empirical Assessment," .

Bhamra, H., and R. Uppal (2006): "The Effect of Risk Aversion and Intertemporal Substitution on Dynamic Consumption and Portfolio Rules with Recursive Utility," Journal of Economic Dynamics and Control, 30(6), 967-991.

Binsbergen van, J. H., J. Fernández-Villaverde, R. S. J. Koijen, and J. F. Rubio-Ramírez (2008): "Likelihood Estimation of DSGE Models with EpsteinZin Preferences," .

Bloom, N. (2009): "The Impact of Uncertainty Shocks," Econometrica, 77(3), 623-685.

Bloom, N., M. Floetotto, and N. Jaimovich (2009): "Really Uncertain Business Cycles," .

Boldrin, M., L. J. Christiano, and J. Fisher (2001): "Habit Persistence, Asset Returns, and the Business Cycle," American Economic Review, 91(1), 149-166.

Bollerslev, T., R. F. Engle, and J. M. Wooldridge (1988): "A Capital Asset Pricing Model with Time-Varying Covariances," Journal of Political Economy, 96(1), 116-131.

Caldara, D., J. Fernández-Villaverde, J. F. Rubio-Ramírez, and W. Yao (2008): "Computing Models with Recursive Preferences," . 
Campanale, C., R. Castro, and G. L. Clementi (2009): "Asset Pricing in a Production Economy with Chew-Dekel Preferences," Review of Economic Dynamics, forthcoming.

Campbell, J. Y., and R. J. Shiller (1988): "Stock Prices, Earnings, and Expected Dividends," Journal of Finance, 43(3), 661-676.

Christiano, L., M. Eichenbaum, and C. Evans (2005): "Nominal Rigidities and the Dynamic Effects of a Shock to Monetary Policy," Journal of Political Economy, 113(1), 1-45.

Croce, M. M. (2008): "Long Run Productivity Risk: A New Hope for Production-based Asset Pricing," .

Eichenbaum, M., L. P. Hansen, and K. J. Singleton (1988): "A Time Series Analysis of Representative Agent Models of Consumption and Leisure Choice under Uncertainty," Quarterly Journal of Economics, 103(1), 51-78.

Epstein, L. G., And S. E. Zin (1989): "Substitution, Risk Aversion, and the Temporal Behavior of Consumption and Asset Returns: A Theoretical Framework," Econometrica, 57(4), 937-969.

(1991): "Substitution, Risk Aversion, and the Temporal Behavior of Consumption and Asset Returns: An Empirical Analysis," Journal of Political Economy, 99(2), 263-286.

Fernández-Villaverde, J., P. Guerron-Quintana, J. F. Rubio-Ramírez, and M. URIBE (2009): "Risk Matters: The Real Ed'ects of Volatility Shocks," .

Garleanu, N., S. Panageas, and J. Yu (2009): "Technological Growth and Asset Pricing," in NBER Working Papers No. 15340.

Gomes, J. F., And L. Schmid (2009): "Levered Returns," The Journal of Finance, forthcoming.

Hansen, L. P., and R. Jagannathan (1991): "Implications of Security Market Data for Models of Dynamic Economies," Journal of Political Economy, 99(2), 225-262.

Jaimovich, N., And S. Rebelo (2009): "Can News about the Future Drive the Business Cycle?," forthcoming.

Jermann, U. J. (1998): "Asset pricing in production economies," Journal of Monetary Economics, 41(2), 257-275.

Justiniano, A., And G. E. Primiceri (2008): "The Time-Varying Volatility of Macroeconomic Fluctuations," American Economic Review, 98(3), 604-641.

Kaltenbrunner, G., and L. A. Lochstoer (2007): "Long Run Risk through Consumption Smoothing," . 
Malkhozov, A. (2009): "Stochastic Volatility and Long-Run Risk in Endowment and Production Economies," .

Malkhozov, A., and M. Shamloo (2009): "Asset Prices in Affine Real Business Cycle Models," .

Ramey, G., and V. Ramey (1995): "Cross-country Evidence on the Link between Volatility and Growth," American Economic Review, 85(5), 1138-1151.

Restoy, F., and M. Rockinger (1994): "On Stock Market Returns and Returns on Investment," Journal of Finance, 49(2), 543-556.

Rudebusch, G. D., and E. T. Swanson (2008a): "The Bond Premium in DSGE Model with Long-Run Real and Nominal Risks," .

(2008b): "Examining the Bond Premium Puzzle with a DSGE Model," Journal of Monetary Economics, forthcoming.

Schmitt-Grohe, S., And M. Uribe (2004): "Solving Dynamic General Equilibrium Models Using a Second-Order Approximation to the Policy Function," Journal of Economic Dynamics and Control, 28(4), 755-775. (2008): "What's News in Business Cycles," .

Sim, J. W. (2006): "Uncertainty, Irreversible Investment and General Equilibrium," .

Swanson, E. T., G. S. Anderson, and A. T. Levin (2006): "Higher-Order Perturbation Solutions to Dynamic, Discrete-Time Rational Expectations Models," in Federal Reserve Bank of San Francisco Working Paper Series 2006-01.

Tallarini, T. D. (2000): "Risk Sensitive Real Business Cycles," Journal of Monetary Economics, 45(3), 507-532.

WeIL, P. (1989): "The Equity Premium Puzzle and the Risk Free Rate Puzzle," Journal of Monetary Economics, 24(3), 401-421. 


\section{A Equilibrium Conditions}

The first order conditions with respect to consumption and labor are respectively:

$$
\begin{aligned}
\left(1-N_{t}\right)^{\eta(1-1 / \psi)} C_{t}^{-1 / \psi} & =-\beta E_{t}\left(V_{t+1}^{1-\gamma}\right)^{\frac{\gamma-1 / \psi}{1-\gamma}} E_{t}\left(V_{t+1}^{-\gamma} V_{K t+1} \frac{\partial K_{t+1}}{\partial C_{t}}\right) \\
-\eta\left(1-N_{t}\right)^{\eta-\eta / \psi-1} C_{t}^{1-1 / \psi} & =-\beta E_{t}\left(V_{t+1}^{1-\gamma}\right)^{\frac{\gamma-1 / \psi}{1-\gamma}} E_{t}\left(V_{t+1}^{-\gamma} V_{K t+1} \frac{\partial K_{t+1}}{\partial N_{t}}\right)
\end{aligned}
$$

The envelope condition with respect to capital implies

$$
V_{K t}=\beta V_{t}^{\frac{1}{\psi}} E_{t}\left(V_{t+1}^{1-\gamma}\right)^{\frac{\gamma-1 / \psi}{1-\gamma}} E_{t}\left(V_{t+1}^{-\gamma} V_{K t+1} \frac{\partial K_{t+1}}{\partial K_{t}}\right)
$$

where

$$
\begin{aligned}
\frac{\partial K_{t+1}}{\partial I_{t}} & =\varsigma K^{\varsigma-1} I^{1-\varsigma} I_{t}^{\varsigma-1} K_{t}^{1-\varsigma}=\phi^{\prime}\left(\frac{I_{t}}{K_{t}}\right) \\
\frac{\partial I_{t}}{\partial C_{t}} & =-1 \\
\frac{\partial I_{t}}{\partial N_{t}} & =\frac{\partial Y_{t}}{\partial N_{t}}=(1-\alpha) Z_{t} A_{t}^{1-\alpha} N_{t}^{-\alpha} K_{t}^{\alpha} \\
\frac{\partial K_{t+1}}{\partial K_{t}} & =(1-\delta)+\frac{\varsigma-1}{\varsigma} K^{-1} I+\frac{1}{\varsigma} K^{\varsigma-1} I^{1-\varsigma}\left(\varsigma K_{t}^{1-\varsigma} I_{t}^{\varsigma-1} \frac{\partial Y_{t}}{\partial K_{t}}+(1-\varsigma) K_{t}^{-\varsigma} I_{t}^{\varsigma}\right) \\
\frac{\partial Y_{t}}{\partial K_{t}} & =\alpha Z_{t}\left(A_{t} N_{t}\right)^{1-\alpha} K_{t}^{\alpha-1}
\end{aligned}
$$

Combining first order conditions (14) and (15), we obtain the condition for optimal consumption-leisure trade-off

$$
-\left(1-N_{t}\right) \frac{\partial K_{t+1}}{\partial N_{t}}=\eta C_{t} \frac{\partial K_{t+1}}{\partial C_{t}}
$$

Finally, the Euler equation can be derived by combining first order conditions (14) and (15), and transversality conditions

$$
E_{t}\left[\beta\left(\frac{V_{t+1}}{E_{t}\left(V_{t+1}^{1-\gamma}\right)^{\frac{1}{1-\gamma}}}\right)^{1 / \psi-\gamma}\left(\frac{C_{t+1}}{C_{t}}\right)^{-1 / \psi}\left(\frac{1-N_{t+1}}{1-N_{t}}\right)^{\eta(1-1 / \psi)}\left(\frac{\partial K_{t+2}}{\partial C_{t+1}}\right)^{-1} \frac{\partial K_{t+1}}{\partial C_{t}} \frac{\partial K_{t+2}}{\partial K_{t+1}}\right]=1
$$




\section{B Stationary Form and the Steady State}

Defining the stationary version of a variable $X_{t}$ as $\tilde{X}_{t}$, where $\tilde{X}_{t}=\frac{X_{t}}{A_{t-1}}$ and defining the stationary version of the value function as $\tilde{V}_{t}$, where $\tilde{V}_{t}=V\left(\tilde{K}_{t}, \tilde{A}_{t}, Z_{t}, \mu_{t}\right)$ we can re-define the equilibrium of the model in terms of the stationary variables. Since the value function is homogeneous of degree one in $K_{t}$ and $A_{t}$

$$
\begin{gathered}
V\left(K_{t}, A_{t}, Z_{t}, x_{t}^{(-1,-2)}\right)=A_{t-1} V\left(\frac{K_{t}}{A_{t-1}}, \frac{A_{t}}{A_{t-1}}, Z_{t}, x_{t}^{(-1,-2)}\right) \\
\frac{V_{t}}{A_{t-1}}=\max _{C_{t}, N_{t}}\left(\left(\left(1-N_{t}\right)^{\eta} \frac{C_{t}}{A_{t-1}}\right)^{1-\frac{1}{\psi}}+\left(\frac{1}{A_{t-1}}\right)^{1-\frac{1}{\psi}} \beta\left(E_{t}\left(V_{t+1}^{1-\gamma}\right)\right)^{\frac{1-\frac{1}{\psi}}{1-\gamma}}\right)^{\frac{1}{1-\frac{1}{\psi}}} \\
\tilde{V}_{t}=\max _{\tilde{C}_{t}, \tilde{N}_{t}}\left(\left(\left(1-N_{t}\right)^{\eta} \tilde{C}_{t}\right)^{1-\frac{1}{\psi}}+\tilde{A}_{t}^{1-\frac{1}{\psi}} \beta\left(E_{t}\left(\tilde{V}_{t+1}^{1-\gamma}\right)\right)^{\frac{1-\frac{1}{\psi}}{1-\gamma}}\right)^{\frac{1}{1-\frac{1}{\psi}}}
\end{gathered}
$$

The optimality conditions can be rewritten as

$$
\begin{aligned}
E_{t}\left[M_{t+1}\left(\frac{\partial \tilde{K}_{t+2}}{\partial \tilde{C}_{t+1}}\right)^{-1} \frac{\partial \tilde{K}_{t+1}}{\partial \tilde{C}_{t}} \frac{\partial \tilde{K}_{t+2}}{\partial \tilde{K}_{t+1}}\right] & =1 \\
-\left(1-N_{t}\right) \frac{\partial \tilde{K}_{t+1}}{\partial N_{t}}-\eta \tilde{C}_{t} \frac{\partial \tilde{K}_{t+1}}{\partial \tilde{C}_{t}} & =0
\end{aligned}
$$

where

$$
M_{t+1}=\tilde{A}_{t}^{-1 / \psi} \beta\left(\frac{\tilde{V}_{t+1}}{E_{t}\left(\tilde{V}_{t+1}^{1-\gamma}\right)^{\frac{1}{1-\gamma}}}\right)^{\gamma-1 / \psi}\left(\frac{\tilde{C}_{t+1}}{\tilde{C}_{t}}\right)^{-1 / \psi}\left(\frac{1-N_{t+1}}{1-N_{t}}\right)^{\eta(1-1 / \psi)}
$$

The capital evolution equation and investment become

$$
\begin{aligned}
\tilde{K}_{t+1} \tilde{A}_{t} & =(1-\delta) \tilde{K}_{t}-\tilde{K}_{t}\left(\frac{1}{\varsigma} \tilde{K}^{\varsigma-1} \tilde{I}^{1-\varsigma}\left(\frac{\tilde{I}_{t}}{\tilde{K}_{t}}\right)^{\varsigma}+\frac{\varsigma-1}{\varsigma} \tilde{K}^{-1} \tilde{I}\right) \\
\tilde{I}_{t} & =Z_{t}\left(\tilde{A}_{t} N_{t}\right)^{1-\alpha} \tilde{K}_{t}^{\alpha}-\tilde{C}_{t}
\end{aligned}
$$

Finally, the non-stationary technology shock is normalized as below, whereas the other 
stationary state variables remain unchanged.

$$
\begin{aligned}
\ln \tilde{A}_{t+1} & =x_{t+1}^{1} \\
\ln Z_{t+1} & =x_{t+1}^{2} \\
x_{t+1} & =H_{0}+H_{1} x_{t}+H_{2} \epsilon_{t+1}
\end{aligned}
$$

The solution for the non-stochastic steady state can be expressed in closed form

$$
\begin{aligned}
N & =\text { const } \\
x & =\left(I-H_{1}\right)^{-1} H_{0} \\
\tilde{A} & =\exp \left(x^{1}\right) \\
Z & =\exp \left(x^{2}\right) \\
\tilde{K} & =(\tilde{A} N)\left[\frac{\beta^{-1} \tilde{A}^{1 / \psi}-(1-\delta)}{\alpha Z}\right] \frac{1}{\alpha-1} \\
\tilde{Y} & =Z(\tilde{A} N)^{1-\alpha} \tilde{K}^{\alpha} \\
\tilde{I} & =(\tilde{A}-(1-\delta)) \tilde{K}^{-1} \\
\eta & =\tilde{C}^{-1}(1-N)(1-\alpha) Z \tilde{A}^{1-\alpha} N^{-\alpha} \tilde{K}^{\alpha} \\
\tilde{V} & =\left[\frac{\left((1-N)^{\eta} \tilde{C}\right)^{1-\frac{1}{\psi}}}{1-\beta \tilde{A}^{1-\frac{1}{\psi}}}\right]^{\frac{1}{\psi}} \\
\tilde{Q} & =\tilde{V}^{1-\gamma}
\end{aligned}
$$




\section{Scaling the Value Function}

In practice value function can take very large or very small values. These would be magnified when evaluating the term $E_{t}\left(\tilde{V}_{t+1}^{1-\gamma}\right)$ which appears in the Euler equation. This can be problematic when numerically evaluating the model. To avoid this issue, we scale the value function such that $\tilde{V}$ takes a reasonable value in the non-stochastic steady state. We note that pre-multiplying $u_{t}^{1-\frac{1}{\psi}}$ by a constant $\Lambda$ scales the value function by $\Lambda^{\frac{1}{1-\frac{1}{\psi}}}$. Moreover this does not have any effect on equilibrium quantities or prices.

$$
\tilde{V}_{t}=\max _{\tilde{C}_{t}, \tilde{N}_{t}}\left(\Lambda\left(\left(1-N_{t}\right)^{\eta} \tilde{C}_{t}\right)^{1-\frac{1}{\psi}}+\tilde{A}_{t}^{1-\frac{1}{\psi}} \beta\left(E_{t}\left(\tilde{V}_{t+1}^{1-\gamma}\right)\right)^{\frac{1-\frac{1}{\psi}}{1-\gamma}}\right)^{\frac{1}{1-\frac{1}{\psi}}}
$$

Therefore, we choose $\Lambda$ such that at the steady state $\tilde{V}=\tilde{V}^{1-\gamma}=1$. 


\section{The Structure for Anticipated Shocks}

Anticipated productivity shocks can be represented as a VAR(1). We present only the non-stationary shocks, as is the case in our benchmark calibration. Adding the stationary shocks is very similar, but are omitted for parsimonious presentation.

$$
\begin{gathered}
\ln A_{t+1}-\ln A_{t}=x_{t+1}^{1} \\
x_{t+1}=H_{0}+H_{1} x_{t}+H_{2} \epsilon_{t+1}
\end{gathered}
$$

where

$$
x_{t}=\left(\begin{array}{c}
x_{t}^{1} \\
\varepsilon_{A, t}^{1} \\
\varepsilon_{A, t}^{2} \\
\varepsilon_{A, t}^{3} \\
\varepsilon_{A, t-1}^{2} \\
\varepsilon_{A, t-1}^{3} \\
\varepsilon_{A, t-2}^{3}
\end{array}\right)
$$

where $\varepsilon_{A, t}^{1}, \varepsilon_{A, t}^{2}$, and $\varepsilon_{A, t}^{3}$ are respectively the 1-quarter-, 2-quarter- and 3-quarter-ahead anticipated component of the non-stationary TFP shock. Also, the autoregressive matrixes are defined as:

$$
H_{0}=\left(\begin{array}{c}
\left(1-\rho_{A}\right) \lambda_{A} \\
0 \\
0 \\
0 \\
0 \\
0 \\
0
\end{array}\right) H_{1}=\left(\begin{array}{ccccccc}
\rho_{A} & 1 & 0 & 0 & 1 & 0 & 1 \\
0 & 0 & 0 & 0 & 0 & 0 & 0 \\
0 & 0 & 0 & 0 & 0 & 0 & 0 \\
0 & 0 & 0 & 0 & 0 & 0 & 0 \\
0 & 0 & 1 & 0 & 0 & 0 & 0 \\
0 & 0 & 0 & 1 & 0 & 0 & 0 \\
0 & 0 & 0 & 0 & 0 & 1 & 0
\end{array}\right) H_{2}=\left(\begin{array}{cccc}
\sigma_{A}^{0} & 0 & 0 & 0 \\
0 & \sigma_{\mu}^{0} & 0 & 0 \\
0 & 0 & \sigma_{\mu}^{1} & 0 \\
0 & 0 & 0 & \sigma_{\mu}^{2} \\
0 & 0 & 0 & 0 \\
0 & 0 & 0 & 0 \\
0 & 0 & 0 & 0
\end{array}\right)
$$




\section{E Endogenous Variance Dynamics}

This appendix illustrates the results of Section 6 using first order approximated dynamics. Let the $z_{y}$ denote various coefficients of the state variables transition and optimal control equations. $x_{t}$ is the vector of state variables other than the volatility. To the first order consumption growth and volatility of consumption growth are

$$
\begin{aligned}
\Delta c_{t+1} & =\Delta c+c_{x} x_{x} x_{t}+(\varphi-1) c_{\sigma} \sigma_{t}^{2}++c_{x} \sigma_{t} \varepsilon_{t+1}+c_{\sigma} \omega \xi_{t+1} \\
\sigma_{c, t+1}^{2} & =(1-\varphi)\left(c_{x}^{2} \theta+c_{\sigma}^{2} \omega^{2}\right)+\varphi \sigma_{c, t}^{2}+c_{x}^{2} \omega \xi_{t+1}
\end{aligned}
$$

Our results show that $c_{\sigma}<0$. Therefore

$$
(\varphi-1) c_{\sigma}>0
$$

and

$$
\operatorname{Cov}_{t}\left(\Delta c_{t+1}, \sigma_{c, t+1}^{2}\right)=c_{\sigma} c_{x}^{2} \omega^{2}<0
$$


Table (1): Common Parameters

\begin{tabular}{clc}
\hline Parameter & \multicolumn{1}{c}{ Description } & Value \\
\hline \hline$\alpha$ & Capital share in production function & 0.34 \\
$\lambda$ & Depreciation of capital & 0.025 \\
$\eta$ & Mean technology growth rate & $0.41 \%$ \\
$N$ & Curvature on leisure & 0 \\
$N$ & Size of labor supply & 1 \\
\hline
\end{tabular}

This table presents the parameters which are kept constant across models I, II, III and IV. They are calibrated at quarterly frequency.

Table (2): Model-specific Parameters

\begin{tabular}{ccccc}
\hline & Model I & Model II & Model III & Model IV \\
\hline \hline Shocks & $\varepsilon_{A}^{0}, \varepsilon_{A}^{i}$ & $\varepsilon_{A}^{0}$ & $\varepsilon_{A}^{0}, \varepsilon_{A}^{i}, \varepsilon_{Z}^{0}, \varepsilon_{Z}^{i}$ & $\varepsilon_{A}^{0}, \varepsilon_{A}^{i}$ \\
$\chi$ & 1.52 & 1.35 & 1.21 & 1.21 \\
$\beta$ & 0.9972 & 0.9972 & 0.9972 & 0.995 \\
$\tau$ & $\infty$ & $\infty$ & $\infty$ & $\infty$ \\
$\gamma$ & 5 & 5 & 5 & 10 \\
$\psi$ & 1.5 & 1.5 & 1.5 & 1.5 \\
\hline
\end{tabular}

This table shows parameter values specific to each news model calibration. They are calibrated at quarterly frequency. 
Table (3): Productivity Shocks Calibration

\begin{tabular}{lc|cc}
\hline \multicolumn{2}{c|}{ Non-stationary } & \multicolumn{2}{|c}{ Stationary } \\
\hline \hline$\rho_{A}$ & 0.14 & $\rho_{Z}$ & 0.89 \\
$\sigma_{A}^{0}(\%)$ & 0.59 & $\sigma_{Z}^{0}(\%)$ & 2.7 \\
$\sigma_{A}^{1}(\%)$ & 2.3 & $\sigma_{Z}^{1}(\%)$ & 0.56 \\
$\sigma_{A}^{2}(\%)$ & 1.3 & $\sigma_{Z}^{2}(\%)$ & 0.56 \\
$\sigma_{A}^{3}(\%)$ & 1.1 & $\sigma_{Z}^{3}(\%)$ & 3.0 \\
\hline
\end{tabular}

This table shows the volatilities and persistence of the stationary and non-stationary components of quarterly productivity news shocks as estimated by Schmitt-Grohe and Uribe (2008). 
Table (4): Macro Results for Models I-IV

\begin{tabular}{lccccc}
\hline & Data & Model I & Model II & Model III & Model IV \\
\hline \hline $\begin{array}{l}\text { Average consumption growth } \\
E(\Delta c) \%\end{array}$ & 1.90 & 1.90 & 1.90 & 1.90 & 1.90 \\
$\begin{array}{l}\text { Vol. of consumption growth } \\
\sigma(\Delta c) \%\end{array}$ & 2.72 & 2.83 & 2.81 & 2.74 & 2.78 \\
$\begin{array}{l}\text { Relative vol. of cons. to output } \\
\sigma(\Delta c) / \sigma(\Delta y)\end{array}$ & 0.52 & 0.48 & 0.53 & 0.24 & 0.47 \\
$\begin{array}{l}\text { Relative vol. of inv. to output } \\
\sigma(\Delta i) / \sigma(\Delta y)\end{array}$ & 3.00 & 3.04 & 2.00 & 2.92 & 3.24 \\
$\begin{array}{l}\text { Correl. of cons. and output growth } \\
\operatorname{corr}(\Delta c, \Delta y)\end{array}$ & 0.49 & 0.19 & 0.97 & 0.35 & 0.20 \\
$\begin{array}{l}\text { Correl. of cons. and inv. growth } \\
\operatorname{corr}(\Delta c, \Delta i)\end{array}$ & 0.40 & -0.14 & 0.93 & 0.19 & -0.12 \\
$\begin{array}{l}\text { Correl. of output and inv. growth } \\
\operatorname{corr}(\Delta y, \Delta i)\end{array}$ & 0.67 & 0.95 & 0.99 & 0.99 & 0.95 \\
\hline
\end{tabular}

This table presents key annualised macroeconomic moments for news Models I-IV. Data are 1947Q1-2008Q4. 
Table (5): Asset Pricing Results for Models I-IV

\begin{tabular}{|c|c|c|c|c|c|}
\hline & Data & Model I & Model ll & Model llI & Model IV \\
\hline \multicolumn{6}{|l|}{ Average risk free rate } \\
\hline$E\left(r_{f}\right) \%$ & 0.97 & 0.88 & 1.12 & 1.42 & 0.25 \\
\hline Volatility of risk free rate & & & & & \\
\hline$\sigma\left(r_{f}\right) \%$ & 0.86 & 0.75 & 0.62 & 0.82 & 0.78 \\
\hline \multicolumn{6}{|l|}{ Entropy of the SDF } \\
\hline$L(M) \%$ & & 10.36 & 8.11 & 6.58 & 42.96 \\
\hline \multicolumn{6}{|l|}{ Consumption claim risk premium } \\
\hline$E\left(r_{c}-r_{f}\right) \%$ & - & 2.32 & 1.90 & 1.48 & 4.57 \\
\hline $\begin{array}{l}\text { Cons. claim excess returns vol. } \\
\sigma\left(r_{c}-r_{f}\right) \%\end{array}$ & - & 5.10 & 4.73 & 4.16 & 4.93 \\
\hline Consumption claim Sharpe ratio & & & & & \\
\hline$E\left(r_{c}-r_{f}\right) / \sigma\left(r_{c}-r_{f}\right)$ & - & 0.46 & 0.40 & 0.36 & 0.93 \\
\hline \multicolumn{6}{|l|}{ Dividend claim risk premium } \\
\hline$E\left(r_{d}-r_{f}\right) \%$ & 6.33 & 0.00 & 0.06 & 0.00 & 0.10 \\
\hline Dividend claim excess returns vol. & 1949 & 004 & 016 & 020 & 0,40 \\
\hline $\begin{array}{l}\text { Dividend claim Sharpe ratio } \\
\text { Dide }\end{array}$ & 19.42 & 0.04 & 0.16 & 0.20 & 0.40 \\
\hline$E\left(r_{d}-r_{f}\right) / \sigma\left(r_{d}-r_{f}\right)$ & 0.33 & 0.09 & 0.40 & 0.02 & 0.19 \\
\hline \multicolumn{6}{|l|}{ Real term premium ( $\sim 30$ year $)$} \\
\hline$E(y-\tilde{y}) \%$ & - & -1.84 & -1.36 & -1.17 & -3.68 \\
\hline
\end{tabular}

This table presents key annualised asset pricing results for news Models I-IV. Data are 1947Q12008Q4. 
Table (6): Aggregate Dividends for Models I and II

\begin{tabular}{lcc}
\hline & Model I & Model II \\
\hline \hline $\begin{array}{l}\text { Correlation of dividend and consumption growth } \\
\operatorname{corr}(\Delta d, \Delta c)\end{array}$ & 0.29 & -0.87 \\
& & \\
Correlation of dividend and output growth & & \\
$\operatorname{corr}(\Delta d, \Delta y)$ & -0.88 & -0.96 \\
& & \\
Correlation of dividend and investment growth & & \\
$\operatorname{corr}(\Delta d, \Delta i)$ & -0.99 & -0.99 \\
& & \\
Autocorrelation of dividend growth & & \\
$\operatorname{corr}\left(\Delta d, \Delta d_{-1}\right)$ & -0.15 & 0.24 \\
$\operatorname{corr}\left(\Delta d, \Delta d_{-2}\right)$ & -0.11 & 0.00 \\
$\operatorname{corr}\left(\Delta d, \Delta d_{-3}\right)$ & -0.07 & -0.03 \\
$\operatorname{corr}\left(\Delta d, \Delta d_{-4}\right)$ & -0.02 & -0.03 \\
$\operatorname{corr}\left(\Delta d, \Delta d_{-5}\right)$ & -0.01 & -0.03 \\
$\operatorname{corr}\left(\Delta d, \Delta d_{-6}\right)$ & -0.01 & -0.03 \\
$\operatorname{corr}\left(\Delta d, \Delta d_{-7}\right)$ & -0.01 & -0.03 \\
\hline
\end{tabular}

This table summarises the properties of aggregate dividends for Model I and II. 
Table (7): Models V and VI Parameters

\begin{tabular}{cccccc}
\hline$\alpha$ & $\delta$ & $\lambda_{A}$ & $\beta$ & $\gamma$ & $\psi$ \\
\hline \hline 0.333 & $1-0.9^{\frac{1}{12}}$ & $\frac{0.02}{12}$ & $0.98^{\frac{1}{12}}$ & 5.00 & 1.50 \\
\hline
\end{tabular}

This table presents the calibration of parameters for Models V (stochastic volatility) and VI. The frequency is monthly.

Table (8): Stochastic Volatility Calibration

\begin{tabular}{ccc}
\hline & Productivity (implied) & Consumption - Bansal and Yaron (2004) \\
\hline \hline$\theta$ & $6.6 \times 10^{-4}$ & $6.1 \times 10^{-5}$ \\
$\varphi$ & 0.987 & 0.987 \\
$\omega$ & $2.6 \times 10^{-5}$ & $2.3 \times 10^{-6}$ \\
\hline
\end{tabular}

This table presents the Bansal and Yaron (2004) calibration for stochastic volatility of consumption growth and the corresponding back-engineered parameters of the variance of productivity growth used to calibrate Model V. In Model VI (benchmark growth model without stochstic volatility) we set the variance of the shock equal to the long term mean $\theta$. The frequency is monthly. 
Table (9): Macro Results for Model V and VI

\begin{tabular}{lccc}
\hline & Data & Model V & Model VI \\
\hline \hline $\begin{array}{l}\text { Average consumption growth } \\
E(\Delta c) \%\end{array}$ & 1.90 & 2.04 & 2.03 \\
$\begin{array}{l}\text { Volatility of consumption growth } \\
\sigma(\Delta c) \%\end{array}$ & 2.72 & 2.71 & 2.58 \\
$\begin{array}{l}\text { Relative volatility of consumption to output } \\
\sigma(\Delta c) / \sigma(\Delta y)\end{array}$ & 0.52 & 0.46 & 0.44 \\
$\begin{array}{l}\text { Relative volatility of investment to output } \\
\sigma(\Delta i) / \sigma(\Delta y)\end{array}$ & 3.00 & 2.17 & 2.55 \\
$\begin{array}{l}\text { Correlation of consumption and output growth } \\
\text { corr }(\Delta c, \Delta y)\end{array}$ & 0.49 & 0.98 & 0.99 \\
$\begin{array}{l}\text { Correlation of consumption and investment growth } \\
\text { corr }(\Delta c, \Delta i)\end{array}$ & 0.40 & 0.90 & 0.98 \\
$\begin{array}{l}\text { Correlation of output and investment growth } \\
\text { corr }(\Delta y, \Delta i)\end{array}$ & & & \\
\hline
\end{tabular}

This table presents key annualised macroeconomic moments for the model with stochastic volatility (Model V) and the no-stochastic volatility benchmark (Model VI). 
Table (10): Asset Pricing Results for Models V and VI

\begin{tabular}{lccc}
\hline & Data & Model V & Model VI \\
\hline \hline $\begin{array}{l}\text { Average risk free rate } \\
E\left(r_{f}\right) \%\end{array}$ & 0.97 & 2.25 & 2.21 \\
$\begin{array}{l}\text { Volatility of risk free rate } \\
\sigma\left(r_{f}\right) \%\end{array}$ & 0.86 & 0.46 & 0.30 \\
& & & \\
Consumption claim risk premium & - & 1.58 & 1.64 \\
$E\left(r_{c}-r_{f}\right) \%$ & & & \\
Consumption claim excess returns volatility & & 4.56 & 4.52 \\
$\sigma\left(r_{c}-r_{f}\right) \%$ & & 0.35 & 0.36 \\
$\begin{array}{l}\text { Consumption claim Sharpe ratio } \\
E\left(r_{c}-r_{f}\right) / \sigma\left(r_{c}-r_{f}\right)\end{array}$ & - & & \\
$\begin{array}{l}\text { Dividend claim risk premium } \\
E\left(r_{d}-r_{f}\right) \%\end{array}$ & 6.33 & 0.02 & 0.03 \\
$\begin{array}{l}\text { Dividend claim excess returns volatility } \\
\sigma\left(r_{d}-r_{f}\right) \%\end{array}$ & 19.42 & 0.30 & 0.30 \\
$\begin{array}{l}\text { Dividend claim Sharpe ratio } \\
E\left(r_{d}-r_{f}\right) / \sigma\left(r_{d}-r_{f}\right)\end{array}$ & 0.33 & 0.07 & 0.10 \\
\hline
\end{tabular}

This table presents key annualised asset pricing results for the model with stochastic volatility (Model V) and the no-stochastic volatility benchmark (Model VI). 
Figure (1): Impulse responses to the non-stationary productivity shocks
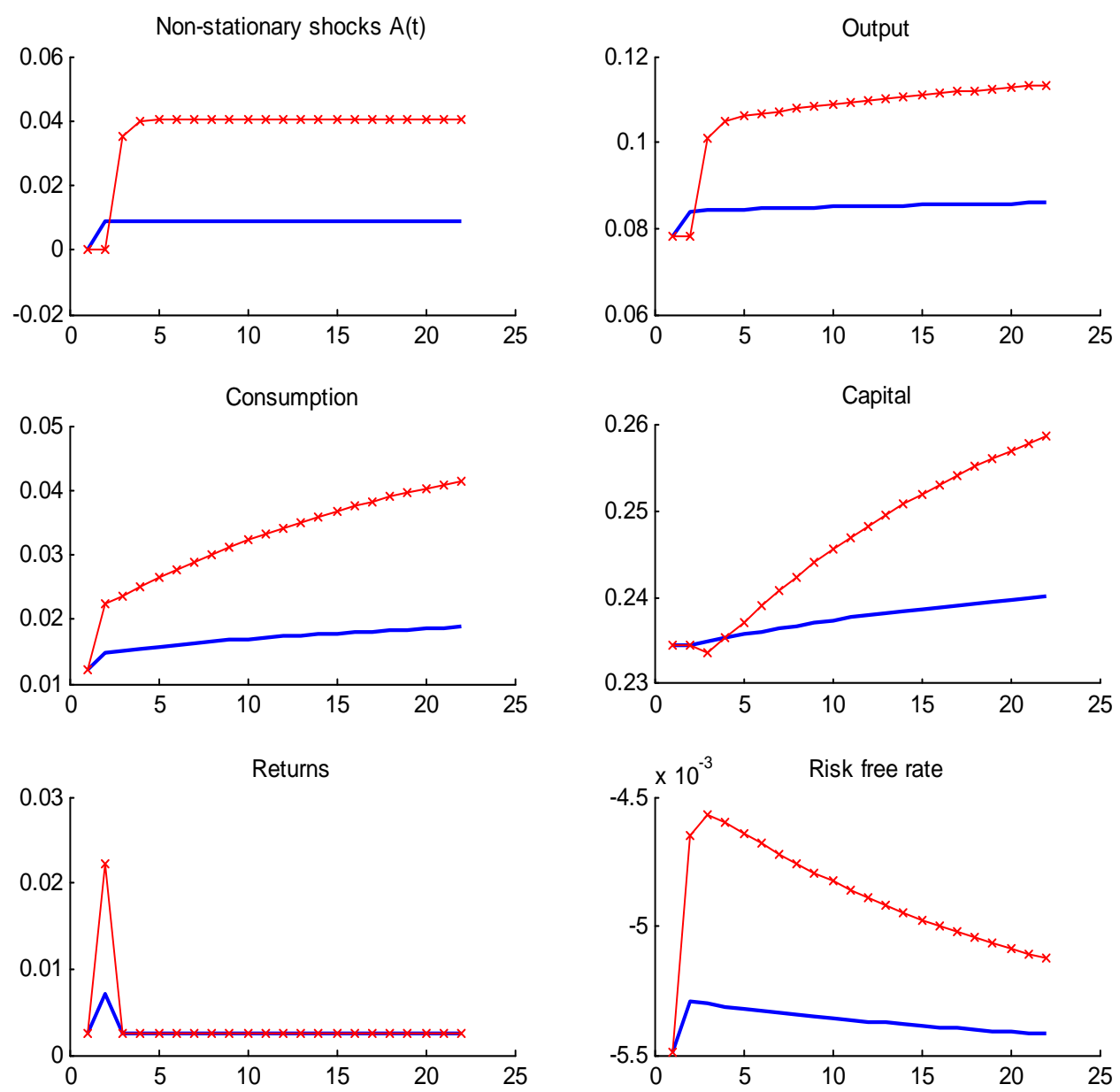

Impulse responses to a one-standard-deviation innovation in the anticipated and unanticipated component of the non-stationary productivity $\left(\varepsilon_{A}^{0}\right.$ : Solid line and $\varepsilon_{A}^{1}$ : Crossed line). 
Figure (2): Impulse responses to the stationary productivity shocks
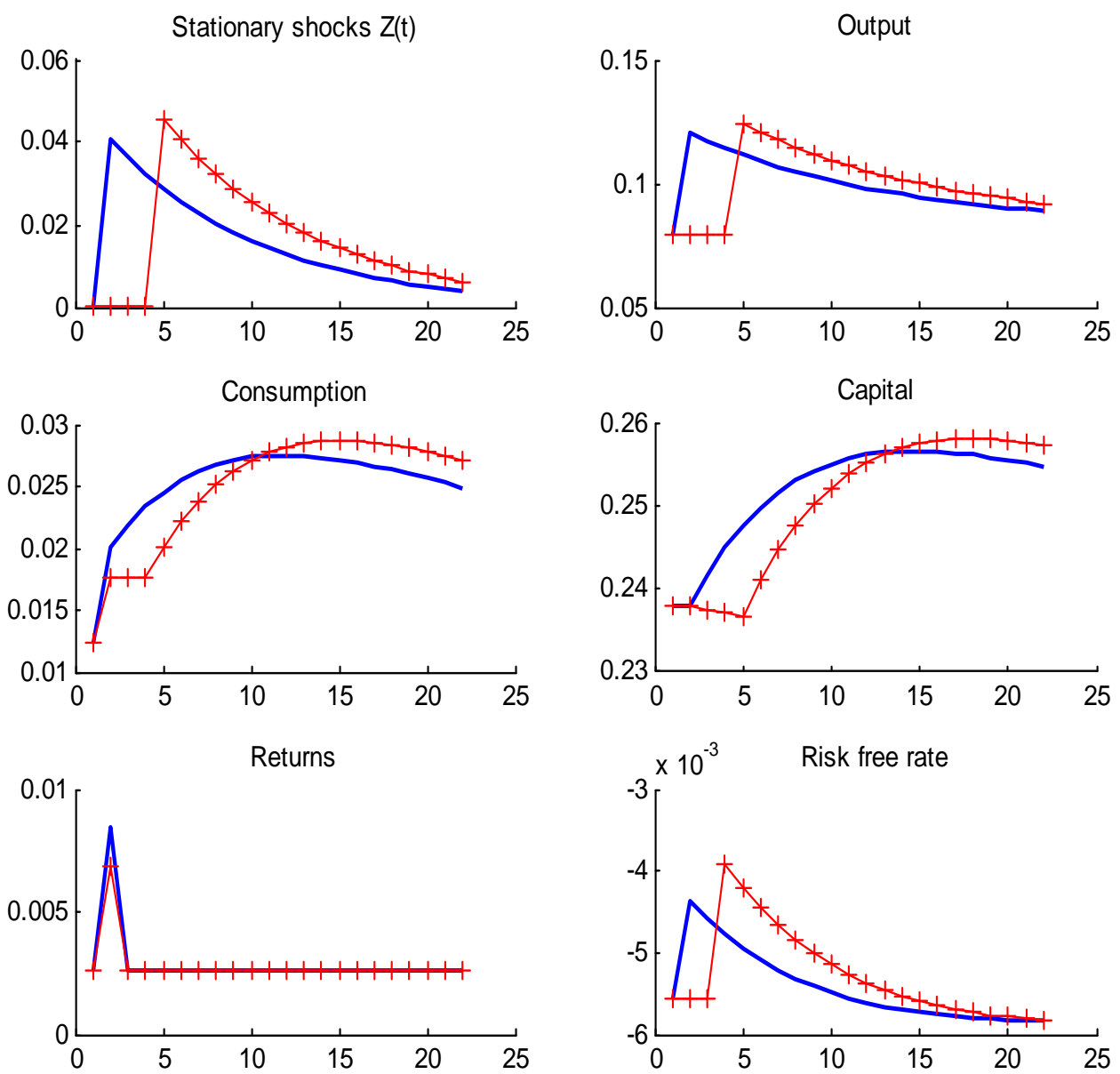

Impulse responses to a one-standard-deviation innovation in the anticipated and unanticipated component of the stationary productivity $\left(\varepsilon_{z}^{0}\right.$ : Solid line and $\varepsilon_{z}^{3}$ : Crossed line). 
Figure (3): Autocorrelation of Quarterly Consumption Growth

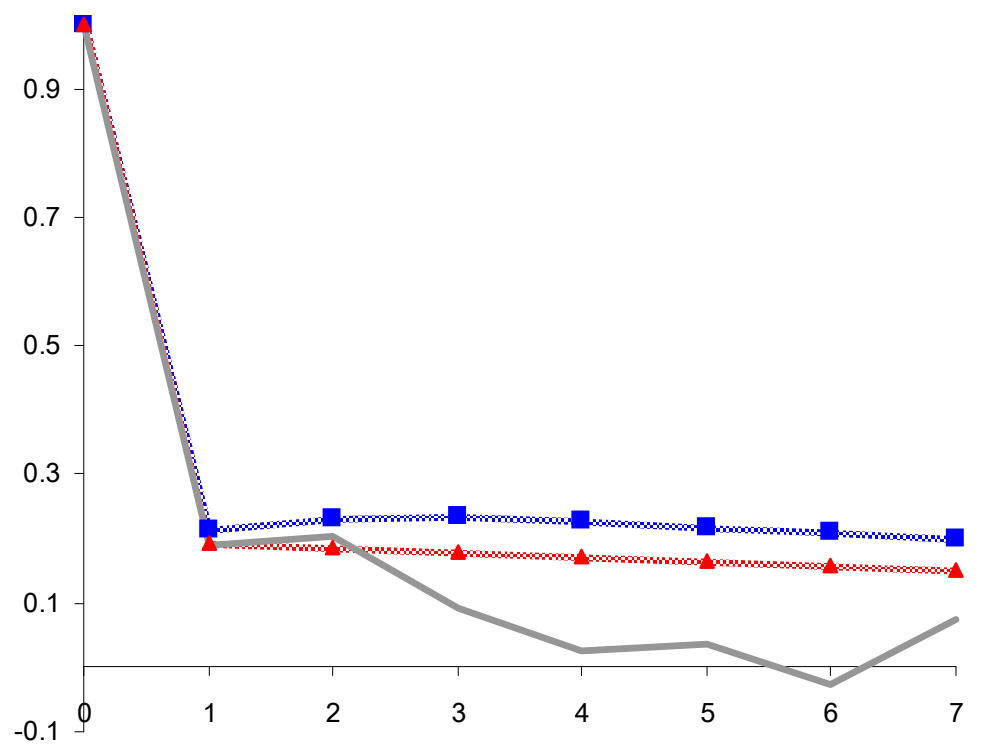

Autocorrelation of quarterly consumption growth. The (ם) line is Model I (news), the (A) line is Model II and the simple line is the data 1947Q1-2008Q4. 
Figure (4): Lead and lag correlations of quarterly returns and output growth

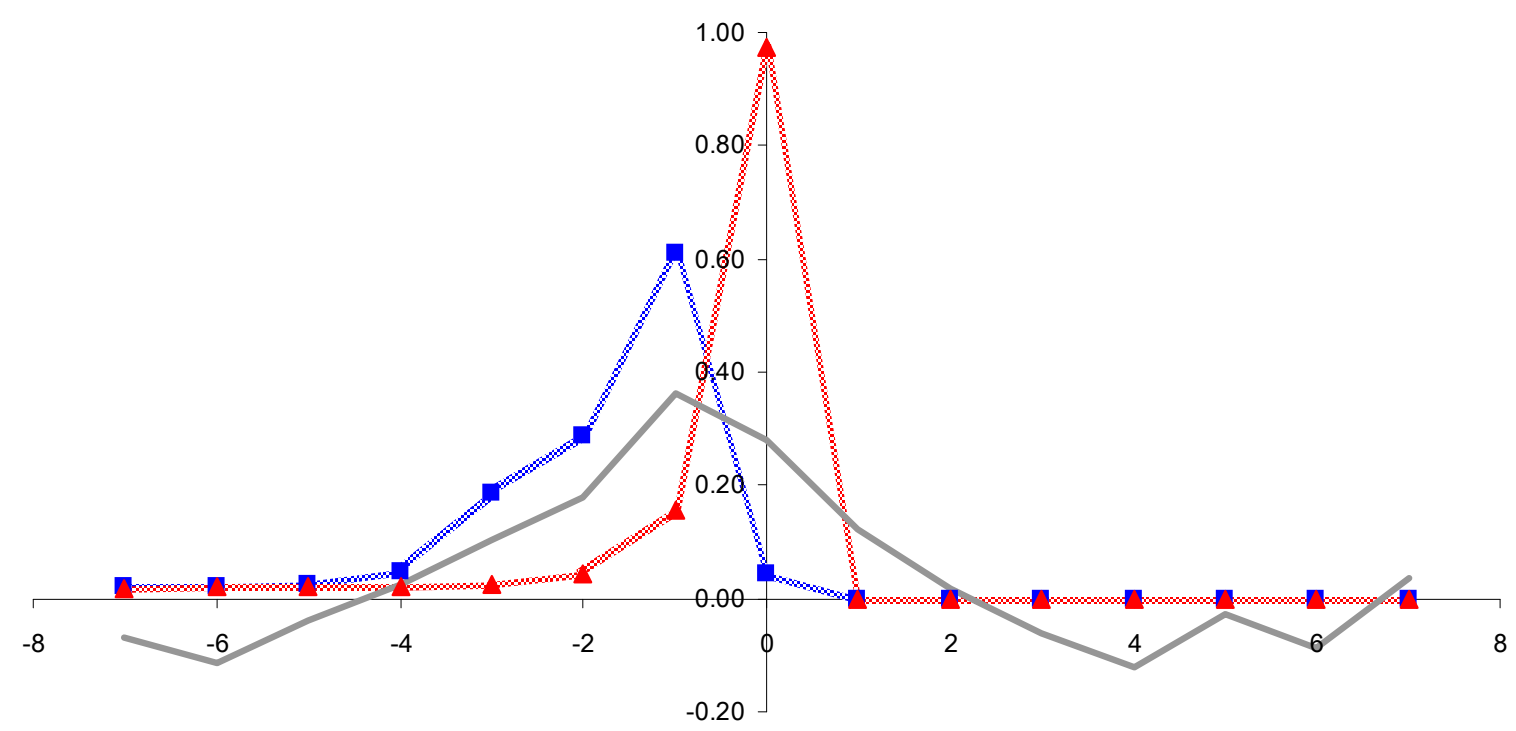

Lead and lag correlation structure of quarterly consumption claim excess returns and output growth. The ( $\mathbf{\square})$ line is Model I (news), the ( $\mathbf{\Delta})$ line is Model II and the simple line is the data 1947Q1-2008Q4.

Figure (5): Lead and lag correlations of quarterly returns and output growth with stationary shocks

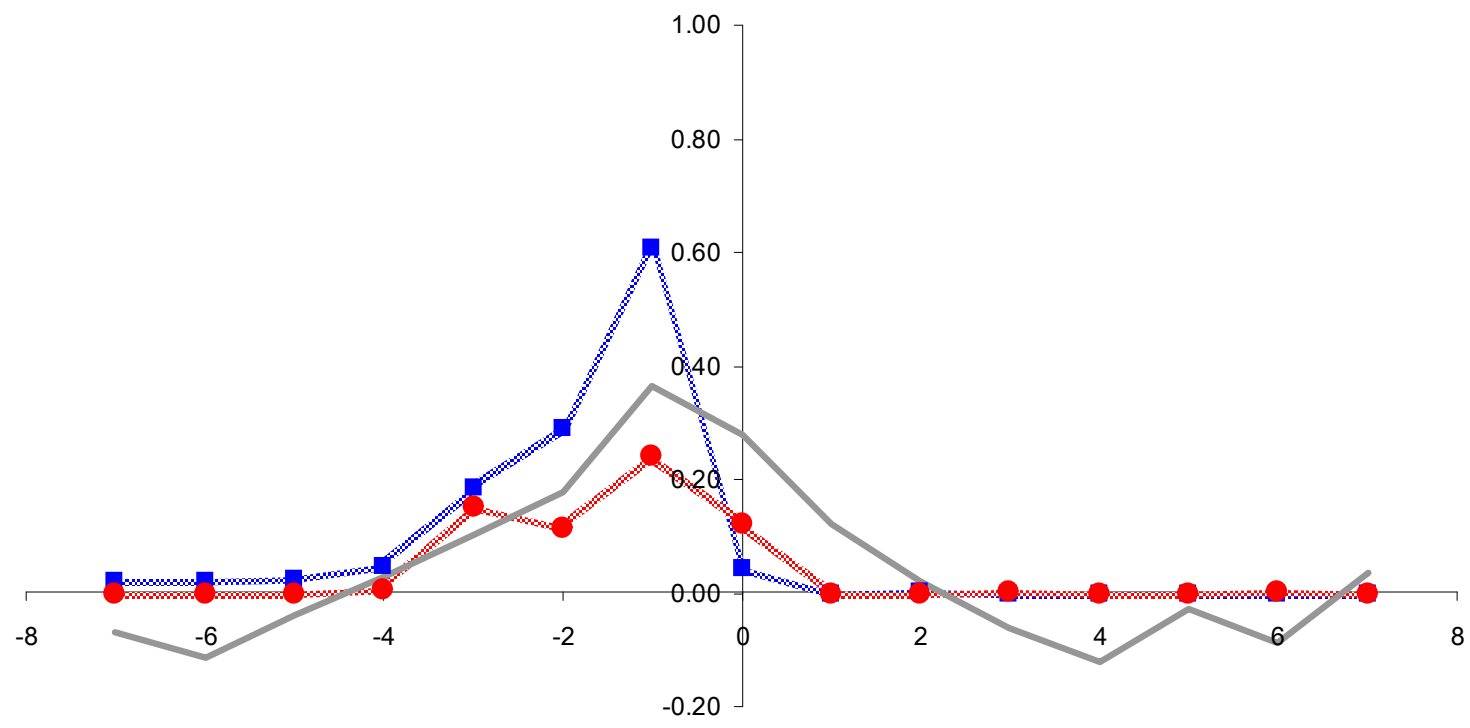

Lead and lag correlation structure of quarterly consumption claim excess returns and output growth. The ( $)$ line is Model I (non-sationary shocks), the (•) line is Model III (both stationary and non-stationary shocks) and the simple line is the data 1947Q1-2008Q4. 
Figure (6): Impulse responses to a productivity variance shock
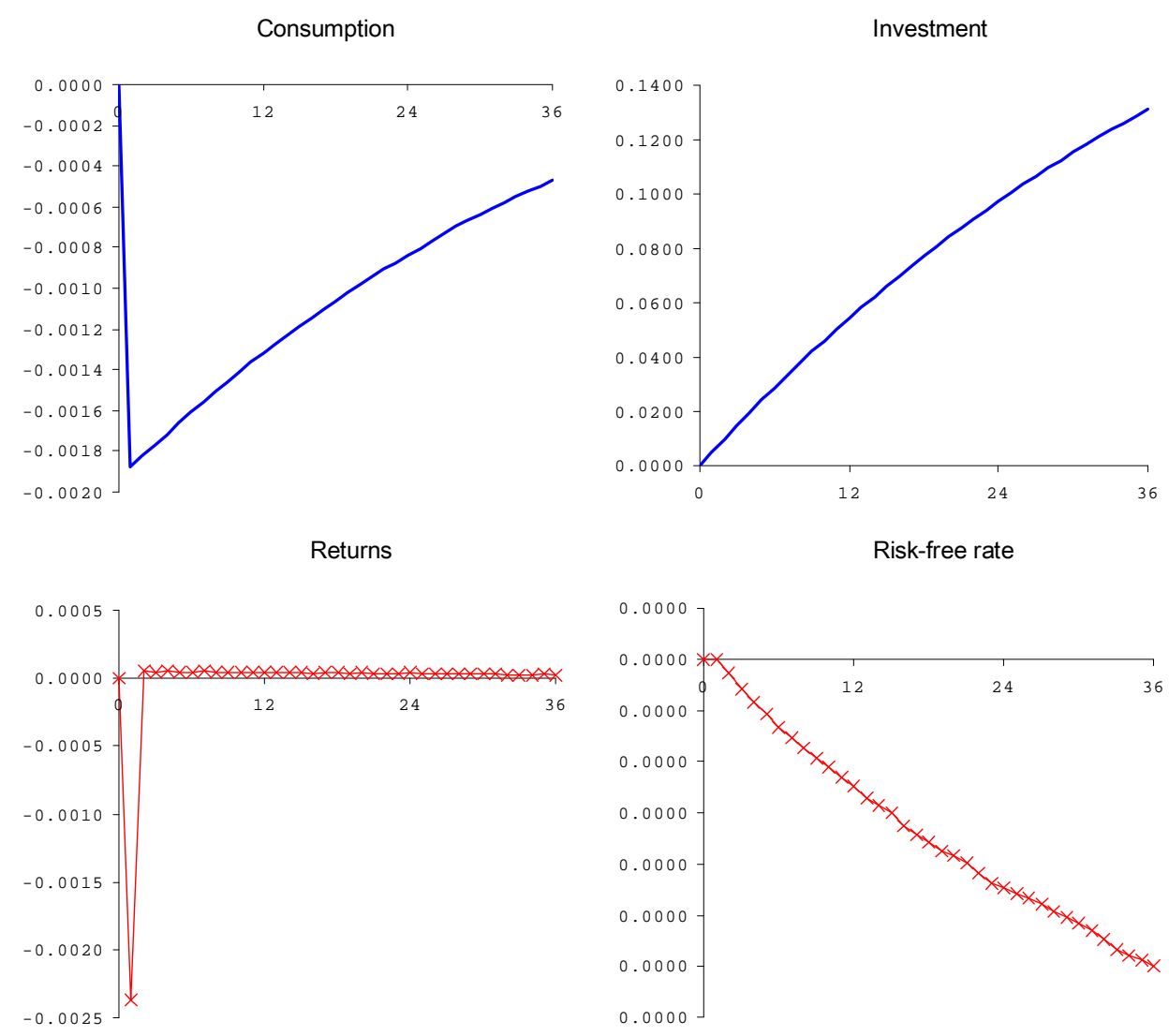

Impulse responses of quantities and prices to a one-standard-deviation shock to the variance of productivity growth in Model V. 
Figure (7): The role of the elasticity of intertemporal substitution
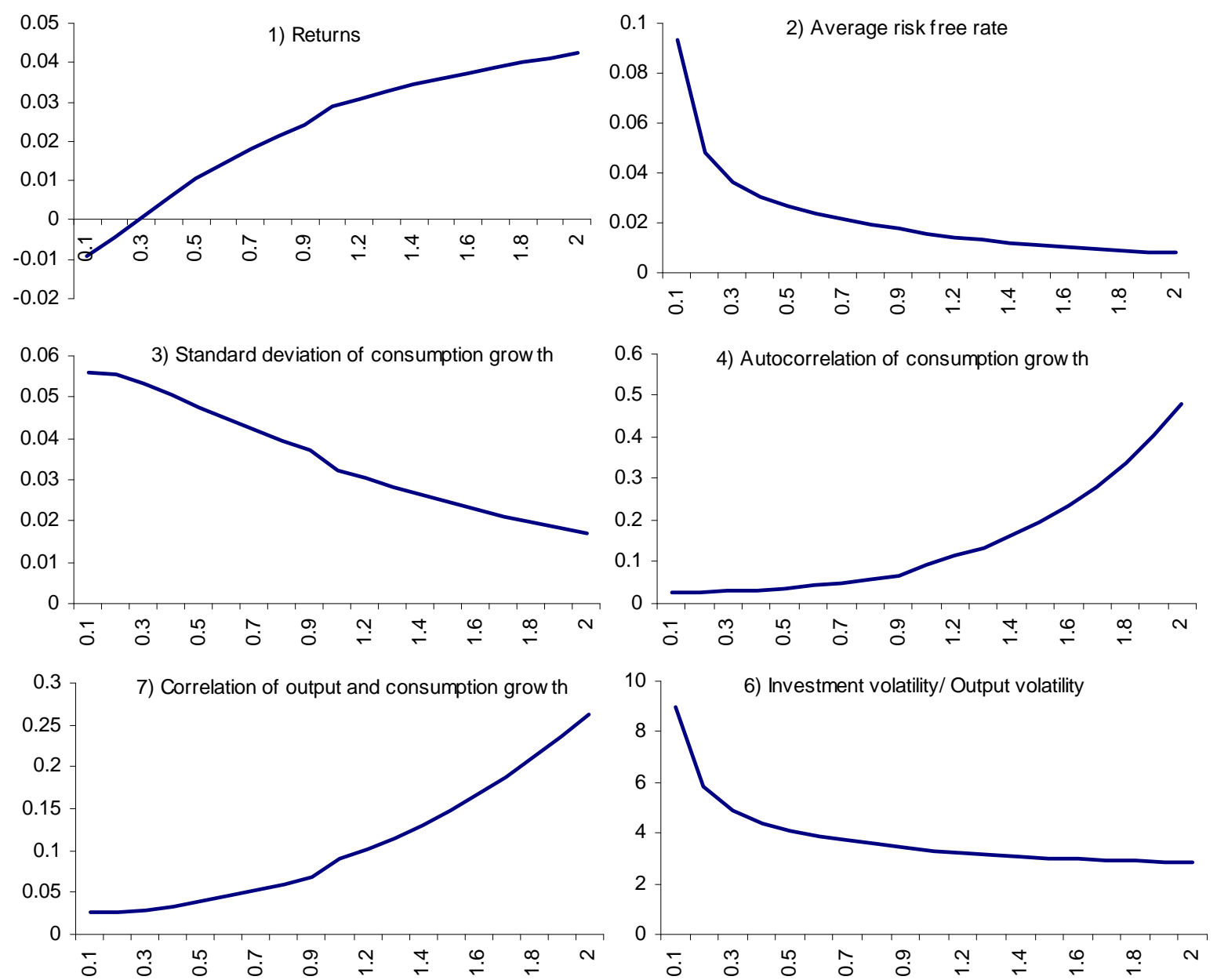

Variation of macroeconomic and financial variables with the elasticity of intertemporal substitution in Model I 